\title{
معوقات تطبيق جودة البيئة التربوية في رياض الأطفال الفلسطينية: دراسة حالة رياض الأطفال في مهافظة سلفيت
}

The Obstacles of Applying the Educational Environment Quality in Palestinian Kindergartens: a Case Study of Kindergartens in Salfit Governorate

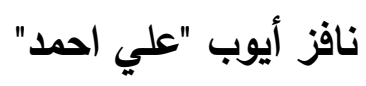

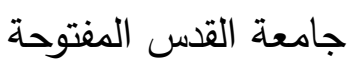


هدفت هذه الدراسة إلى التعرف على الصعوبات التي تحول دون تحقيق جودة البيئة التربوية في رياض الأطفال، ووضع مقترح لضمان جودة البيئة التربوية في رياض الأطفال. وقد استخدمت الدراسة المنهج الوصفي. واستخدِمت الاستبانة كأداة للدراسة، وتكون مجتمع الدراسة من (174) مديرة ومربية يعملن في (58) روضة في محافظة سلفيت، وتكونت عينة الدراسة بنسبة 100\% من مجتمع الدراسة، واستخدم البرنامج الإحصائي (SPSS) في تحليل البيانات واستخراج النتائج، وتوصلت الدراسة إلى مجموعة من المعوقات لتطبيق جودة البيئة التربوية في رياض الأطفال من أهمها: عدم كفاية الموارد المالية المتوافرة لشراء الوسائل والألعاب، عدم كفاية الألعاب التعليمية، عدم كفاية الوسائل التعليمية، عدم توافر أجهزة حاسوب، التركيز على التعليم على حساب المهارات، قلة الرحلات الترفيهية. الكلمات المفتاحية: البيئة التربوية في رياض الأطفال، الجودة، مربية الروضة، روضة الأطفال، طفل

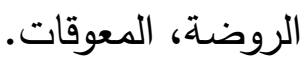

\section{Abstract:}

This study aims to identify the difficulties which prevent achieving the quality of the educational environment in kindergartens and to develop a proposal which ensures the quality or good atmosphere of the educational environment in kindergartens. The researcher used the descriptive approach through a questioner which was used as a tool for study. The study population consisted of a total of (174) principals (headmasters) and teachers who worked hand in hand in (58) kindergartens in Salfit Governorate. The study sample consisted of (100\%) of the study population. The (SPSS) program has been used to analyze the data and extract results. The study clarified that there are insufficient financial resources to purchase equipment, materials and educational games, also the kindergartens lack much of computer devices, focus on the education at the expense of skills and the lack of leisure trips.

Keywords: Educational environment in kindergartens, the quality, Kindergarten teacher, Kindergarten, kindergarten child or kid, Obstacles.

تعد مرحلة الطفولة من أهم الفترات في تكوين شخصية الفرد، فهي مرحلة تكوين وإعداد؛ فيها تُرسم ملامح شخصية الفرد مستقبلاً، وفيها تتثكل العادات والاتجاهات وتتمو الميول والاستعدادات وتتثتح القدرات وتتكون المهارات وتتكثف (شريف، 2014). وتُمثل القيم الروحية والتقاليد والأنماط السلوكية 
(قطامي، 2008). وخلالها يتحدد مسار نمو الطفل الجسمي والعقلي والنفسي والاجتماعي والوجداني طبقا لما توفره له البيئة التربوية في رياض الأطفال الدحيطة بعناصرها التربوية والثقافية والصحية والاجتماعية، لذا فإن تجويد البيئة في الروضة يحقق التربية المتكاملة للطفل، وينمو بطريقة سوية (لبابنه، 2010؛ عليمات، 2004). وكذلك حظيت البيئة التربوية وجودتها في مؤسسات رياض الأطفال باهتمام بالغ من قبل المربين وعلماء النفس والفلاسفة، ومنهم الفيلسوف روسو (Rousseau) الذي يعد من أوائل المنادين بضرورة الاهتمام بالطفولة المبكرة، ومراعاة احتياجاتها ومتطلباتها، وسنحت الفرصة للعالمين فروبل وماريا مونتسوري ليطبقا تلك الأفكار، فأنشآ دور رياض الأطفال، حيث تهتم تلك الدور بتقديم العناية والرعاية للأطفال، بالإضافة إلى تعليمه بعض المبادئ الأساسية عن طريق اللعب، مع الاهتمام بتتمية الطفل

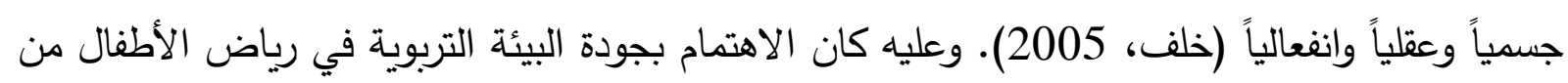
أهم المعايير التي يقاس بها تقدم الثعوب (Woods, 2010)، فهي تثكل منظومة من منظومات المجتمع، وبالتالي فالنهوض بجودة مؤسسة رياض الأطفال سيكون خطوة في سبيل النهوض بالمجتمع ككل (عبدالحميد، 2008؛ Wolff, 2006 ; 2002 (Owens, 2002

وتتعدد الجهات التي تدير مؤسسات رياض الأطفال في فلسطين، إذ يسيطر القطاع الخاص الربحي على إدارة معظم مؤسسات رياض الأطفال، والمنظمات غير الحكومية، والمنظمات الدينية (اليونيسيف، 2009)؛ إضافةً للقطاع الحكومي. كل هذا يستدعي جهوداً حثيثة من جميع الأطراف لدعم هذا القطاع والعمل على تطويره في فلسطين، والقيام بالإشراف الدقيق المباشر على هذه المؤسسات؛ لمراقبة ما يجري داخلها خاصة مع تعدد التوجهات والمرجعيات والمؤهلات، سواء للمالكين أو المشرفين أو للمستثرين الذين يديرون هذه الرياض (السرور، 1999). وكنلك ضرورة معرفة إلى أي حدٍ توفر هذه المؤسسات المتطلبات الأساسية للنمو المتكامل والسليم لطفل الروضة، وإلى أي حدٍ تلتزم هذه المؤسسات بمعايير وشروط ترخيص رياض الأطفال، خاصة إذا ما عرفنا أن البيئة التي يتواجد بها الطفل لها علاقة مباشرة بنموه العقلي والمعرفي والجسمي والاجتماعي؛ وعليه يجب توفير بيئة تربوية غنية بالمثيرات الحسية لمساعدة الطفل على النمو بشكل سليم. إن البيئة التربوية في مؤسسات رياض الأطفال الفقيرة بالمثيرات غالبا ما تقتصر على إثباع جانب أو أكثر من جوانب نمو الطفل، مما يؤدي إلى حرمانه من عوامل معينة، وقد يصل هذا الحرمان إلى إعاقة نموه، ليس بفعل عوامل وراثية، ولكن لأسباب ترجع إلى قصور بيئي يتعرض له اله الطفل 
(الزواوي، 2003؛ بهادر، 2003؛ الشتيحي، 2015). أما البيئة الغنية بالمثيرات فإنها تعمل على تعريض الأطفال لخبرات تعليمية مكثفة؛ بحيث تزودهم بالمعلومات والخبرات والمهارات التي تكثف عن قدراتهم، وتُقتح لهم طاقاتهم، وتوفر لهم إنعاشاً وإثراءً في جوانب نموهم المختلفة (ابو دقة، 2007؛ .(Sulrana, 2008

تتناول الدراسة الحالية معوقات تطبيق جودة البيئة التربوية في مؤسسات رياض الأطفال في فلسطين بهدف الارتقاء بمستوى أداء تلك المؤسسات، ولتحقيق ذلك؛ يجب الاهتمام بها لتحسين مستوى هئ أدائها من خلال تطبيق معايير الجودة، إذ تتبهت معظم دول العالم إلى أهمية الجودة في التعليم، فوضعتها في صدر أولوياتها منذ تسعينيات القرن الماضي.

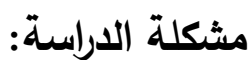

اقتصر البحث الحالي على دراسة الإمكانات المادية والفنية في الروضة وما توفره من مواصفات وتجهيزات كونها البيئة التربوية التي تحتضن الطفل والدكان الذي يطور فيه خبراته، ويعتقد الباحث من خلال خبرته واطلاعه على واقع رياض الأطفال في فلسطين كونه عمل رئيساً لقسم التعليم العام في وزارة

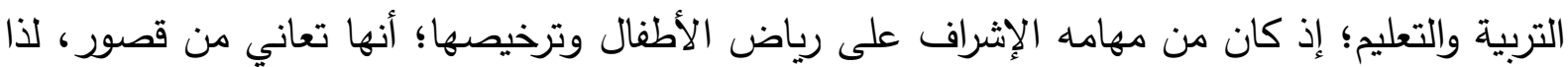

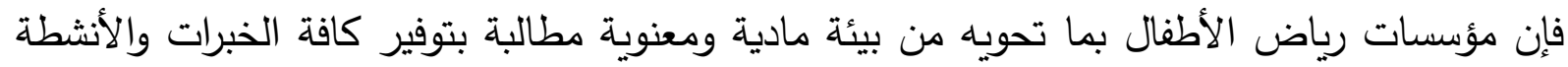

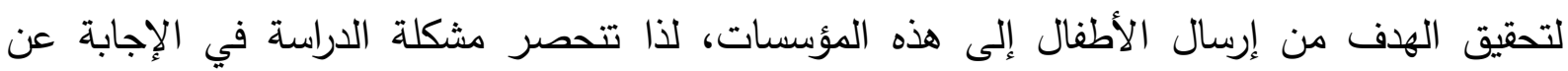

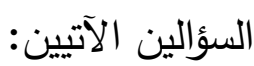

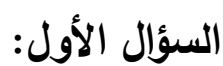
"ما معوقات تطبيق جودة البيئة التربوية في رياض الأطفال من وجهة نظر مديرات ومربيات رياض الأطفال في سلفيت حسب مجالي (المعوقات المادية، المعوقات الفنية)؟"

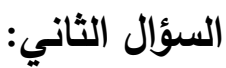
"هل توجد فروق ذات دلالة إحصائية لمعوقات تطبيق جودة البيئة التزبوية في رياض الأطفال من وجهة نظر مديرات ومربيات الرياض في فلسطين تعزى لمتغيرات الدراسة: طبيعة العمل، المؤهل العلمي،

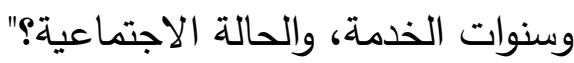
أهداف الدراسة: تسعى الدراسة إلى تحقيق الأهداف الآتية: 1. التعرف على المعوقات المادية والفنية التي تحول دون تطبيق جودة البيئة التربوية في رياض الأبة الطفال في فلسطين. 
2. التعرف على الفروق الإحصائية لمعوقات تطبيق جودة البيئة التزبوية في رياض الأطفال من وجهة نظر مديرات ومربيات الرياض في فلسطين تعزى لمتغيرات الدراسة: طبيعة العمل، المؤهل العلمي، وسنوات الخبرة، والحالة الاجتماعية.

أهمية الدراسة:

انطلاقاً من أهمية مرحلة رياض الأطفال وأهمية تجويد التربية في هذه المرحلة وتجويد البيئة التربوية في الروضة بما توفره من مواصفات وتجهيزات وإمكانات مادية وفنية؛ يمكن تلخيص أهمية

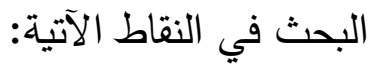
الأهمية النظرية: قد تقيد الدراسة في الآتي: 1. تعرف تجارب بعض الدول فيما يتعلق بتجويد التربية والاستفادة من تجاربها في وضع أسس تضمن جودة التربية في رياض الأطفال. 2. زيادة الوعي لقطاعات المجتمع وأفرادها بأهمية مرحلة رياض الأطفال في تكوين ملامح شخصية

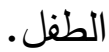
3. يعد استجابة لما أوصت به العديد من الدراسات بضرورة الاهتمام بالجودة في مرحلة رياض الأطفال والسعي نحو تتميتها مثل (أحمد، 2007؛ سعفان، 2008؛ راشد وحسين، 2011؛ الشتيحي، 2015). الأهمية التطبيقية: قد تفيد الدراسة في الآتي: 1. قد يصل البحث إلى معايير تساعد في ضمان جودة البيئة التربوية في رياض الأطفال. 2. قد يصل البحث إلى مجموعة من المقترحات التي قد تساهم في مساعدة المسؤولين على وضع أسس تتعلق بجودة البيئة التربوية في مؤسسات رياض الأطفال. 3. قد يفيد البحث الجهات المسئولة عن الأبنية التعليمية في وضع نماذج خاصة لمبنى رياض الأطفال بما يتقق مع المتطلبات النمائية لطفل هذه المرحلة. 4. اعتبار الدراسة مدخلاً لتطور معايير جودة البيئة التربوية تتعامل مع احتياجات أطفال الروضة مبرات إجراء الدراسةتات التي يعانون منها. تكمن مبررات إجراء الدراسة في تحديد معوقات تطبيق جودة البيئة التزبوية في مؤسسات رياض الأطفال من خلال دراسة علمية وذلك للأسباب الآتية:

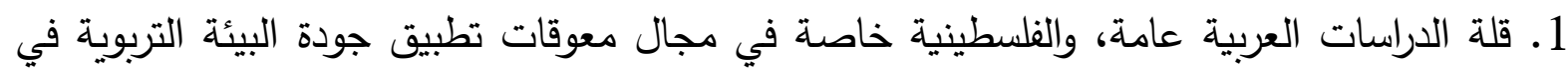
رياض الأطفال في حدود علم الباحث. 
2. ضرورة تحسين برامج الطفولة المبكرة وخاصة في رياض الأطفال في فلسطين بمشاركة المعنيين من المجتمع المحلي. 3. الحاجة إلى الارتقاء بجودة الخدمات المقدمة لقطاع الطفولة المبكرة في فلسطين. 4. تمكين العاملين والفاعلين في مجال رياض الأطفال من خلال إعطائهم الفرصة؛ للتعبير عن التحديات والمشاكل التي تواجههم. حدود الاراسة: الحدود الزمنية: الفصل الدراسي الثاني من العام الدراسي 2019/2018. الحدود المكانية: جميع رياض الأطفال المرخصة من وزارة التربية والتعليم في محافظة سلفيت. الحدود البشرية: جميع مديرات ومربيات رياض الأطفال المرخصة من وزارة التربية والتعليم في محافظة سلفيت. 4. الحد الموضوعي: التطبيق الفعلي لما أسفرت عنه نتائج هذه الدراسة داخل رياض الأطفال وذلك بعد تزويد المسؤولين بها. التعريفات الإجرائية للمصطلحات: 1. البيئة التربوية في رياض الأطفال: كل الدكونات المتعلقة بالروضة والتي قد يكون لها تأثير على تتشئة الطفل من عوامل داخلية أو خارجية سواء كانت مادية أو بشرية، وتقوم على أسس تربوية ونفسية.

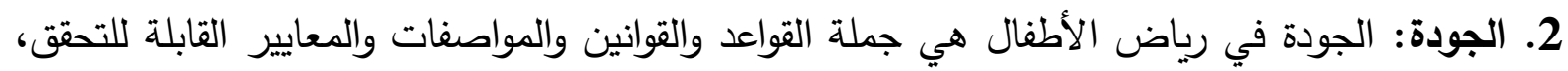
ليتم الانتقال من ثقافة الحد الأدنى إلى ثقافة الإتقان والتميز. 3. مربية الروضة: هي المربية التي تعمل تحت إثراف وزارة التربية والتعليم في إحدى مؤسسات رياض

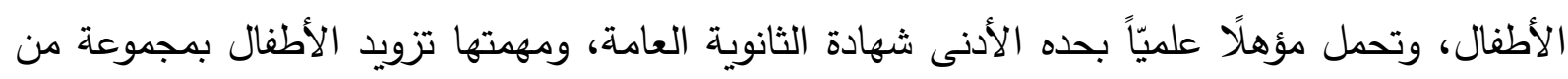
الخبرات تساعدهم على التكيف، وتؤهلهم لاخول المدرسة بسلاسة. 4. روضة الأطفال: هي إحدى المؤسسات التربوية التي تحمل ترخيصاً من وزارة التربية والتعليم، وتستقبل الأطفال من عمر (4-6) سنوات قبل دخولهم المدرسة، وتهدف إلى تحقيق النمو المتكامل للطفل. 5. طفل الروضة: هو الطفل الملتحق بإحدى مؤسسات رياض الأطفال وعمره يقع بين (4-6) سنوات. 6. المعوقات: الصعوبات المتعلقة بعناصر البيئة التربوية في روضة الأطفال والتي تحول دون تحقيق الحد الأعلى من مستوى الأداء. 
الإطار النظري والدراسات السابقة:

الإطار النظري:

انطلاقاً من دعوات الإصلاح التربوي في الوطن العربي؛ توجه التربويون نحو وضع معايير تضمن إصلاح البيئة التربوية وتجويدها في مؤسسات رياض الأطفال مستفيدين من تجارب الدول المتقدمة والتي سبقتها في وضع معايير للجودة التي تعمل على تحسين البيئة التربوية في تلك المؤسسات كتجربة مدينة دترويت في أمريكا عام (1990)، وتجربة الممكة المتحدة عام (1990)، والتجربة اليابانية التي تبنت نظام بيت الجودة في الإصلاح التربوي الثامل (أحمد، 2007)، وحظي المجال المتعلق بإعداد البيئة التربوية في رياض الأطفال وتجهيزاتها باهتمام واضح، وذلك لأنها الوعاء الذي تُصب فيه الخبرات المقدمة للطفل، والثكل الذي يُستثر من خلالها طاقاته؛ لذلك، فإن هذا الثكل إما أن يكون وظيفياً ملائماً لانطلاق تلك الطاقات، أو قد يكون بعيداً عن حاجات الطفل ولا يسهم في تطوير قدراته، وقد سمي طفل الروضة "بالطفل الفعال" لأنه ينهمك بكل طاقاته في النشاط، ويكتسب خبرات تشمل معارفه ومهاراته وعواطفه، وذلك إن وجد في بيئة تربوية فعالة ونشطة وغنية (Froment, 2004). وعليه لا بد من وجود تصور معماري لبناء الروضة يتمتع بمعايير لضمان جودة البيئة التربوية في رياض الأطفال مما يسهم في تجويد العمل التربوي، ومزود بمواصفات خاصة من حيث التجهيزات والأثاث، بحيث ثُقدم هذه المواصفات خدمات أفضل للمستثيدين من جهة، وترقى بالعملية التربوية من جهة أخرى، وأنه بغياب تلك المعايير والمواصفات تبقى الروضة عبارة عن تجمع تقليدي يتكون من غرف هـ متلاصقة، تحتوي على أثاث يشبه الددارس الابتدائية التقليدية؛ لا يساعد المربية على القيام بعملها من جهة، ولا يحقق الأهداف النمائية المرجوة في مرحلة رياض الأطفال من جهة أخرى (علي أحمد، 2017؛ صاصيلا، 2010؛ العليمات، 2013). يمكن تلخيص أهمية جودة البيئة التربوية في مؤسسات رياض الأطفال بالاتي: 1. تحقيق النتائج المتوقعة بتزويد طفل الروضة بخبرات تتتاول معارفه ومهاراته ومشاعره وعواطفه بأقل تكلفة وأقل جهد وأقصر وقت ممكن. 2. تحقيق الأهداف النمائية لأطفال الرياض بما يتماشى مع الظروف المادية والإمكانات البشرية لتلك الرياض بشكل تفاعلي وتعاوني. 3. ربط الروضة بالمجتمع وذلك بفتح أبواب التعاون ما بين الروضة والمجتمع المحلي. 
4. تجنب الوقوع بالأخطاء بدلاً من معالجتها، وذلك بفضل التعاون والمشاركة، ووضع الخطط والإستراتيجيات والتحقق منها قبل التنفيذ. 5. العمل على التطوير المستمر للإمكانات المادية والبشرية العاملة في الروضة من خلال التدريب والتقويم المستمر ، ومن خلال التركيز على مفاهيم وتبنيها مثل: تجويد التجويد، وتطوير التجويد، وتحسين

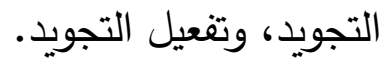
عناصر جودة البيئة التربوية في مؤسسات رياض الأطفال: ورد في دراسات كل من (صاصيلا، 2010؛ فائد، 2013؛ الزبون، 2017؛ سليمان، 2018؛ السنيدي، 2012؛ 2008 (Tungkunanan, Leekitchwatana, Pimsarn \& Chumnum, أهم عناصر جودة البيئة التزبوية في مؤسسات رياض الأطفال، إذ تم حصرها في سبعة عناصر ، هي:

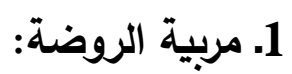

تعد مربية الروضة من الأركان الأساسية في عملية تطوير العملية التربوية في الروضة، لذلك يعد الاهتمام بالجانب المهني للمربية حجر الأساس في تكوين المربية ومعايير جودتها، وحددت مجالات الاهتمام بجودة مربية الروضة عدة معايير تتعلق ببرامج إعدادها في كليات رياض الأطفال في الجامعات وهي: عملية القبول، والمقررات، والتقويم، والجانب الثقافي، والجانب المهني، وزيادة ساعات التربية العملية، وأساليب تنظيم الأركان والأنثطة، وأساليب التفاعل في أثناء النشاط.

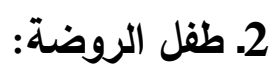

ويعد محور العملية التربوية وهدفها في مرحلة الروضة، إذ تتصب غاية الأنثطة كافة نحو تحقيق الأهداف النمائية له، وتهدف مكونات الروضة من مربيات وإدارة وعاملين إلى تهيئة كافة الظروف والثروط الملائمة لتحقيق نموه وتطوره، وحددت مجالات الاهتمام بجودة طفل الروضة بعدة معايير تتعلق بشخصيته وهي المعايير : الصحية، والنفسية، والاجتماعية، والمعرفية. 3. إدارة الروضة وتشريعاتها ونظمها: وتعد أحد المكونات الأساسية لتجويد عناصر البيئة التربية في مؤسسات رياض الأطفال، وتعد الإدارة الجهة المشرفة والموجهة لكل ما يدور في الروضة، وحددت مجالات الاهتمام بتجويد أداء إدارة الروضة بمجموعة من المعايير والتي تتمثل في: إدراك مفاهيم جودة العمل التربوي في الروضة، والإيمان بأهية التطوير والتجديد والتغيير ، وإتباع إستراتيجيات الجودة وأساليبها ومداخلها، ومتابعة وتوجيه مربيات الروضة ومشرفاتها بشكل دائم، والتشبيك والتفاعل مع مكونات المجتمع المختلفة من الوزارات والمؤسسات 
التي تُعنى بثؤون الطفل ووسائل الإعلام المختلف؛ إضافة إلى أولياء الأمور ، والإيمان بالتطوير المستمر من خلال المشاركة بالدورات التدريبية المتعلقة بالعمل الإداري والتربوي، إضافة إلى إدراك أهمية التقويم المستمر للعاملين في الروضة من كوادر إدارية وتربوية. أما فيما يتعلق بنظم الروضة وتشريعاتها التي تهدف إلى ضبط وتوجيه العمل في مؤسسة الروضة فيمكن حصرها في المعايير الآتية: 1. وضع معايير لقبول الطفل في مؤسسات مرحلة رياض الأطفال معتمدة على العمر الزمني ومدى

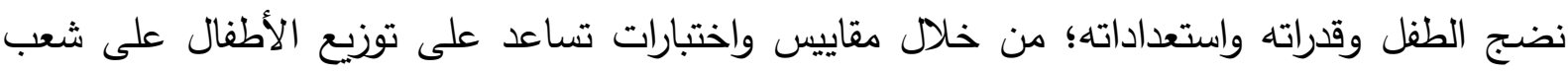
النشاط أسوة ببعض الدول المتقدمة التي تتبل الأطفال وتوزعهم على شعب النشاط في الروضة بالاعتماد

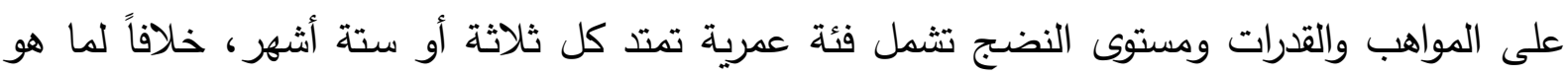
شائع لدينا في فلسطين من تقسيم شعب النشاط تقسيماً سنوياً. 2. التوزيع الزمني اليومي: تتبنى معظم الرياض في الوطن العربي بما فيها فلسطين نظام الحصة المدرسية التقليدية والتي يبلغ زمنها ما يقارب (40) دقيقة، وهذا النهج يتعارض مع طبيعة وخصائص الطفل، ويتعارض كذلك مع نتائج الدراسات التربوية الحديثة في هذا المجال والتي تؤكد على تبني نظام

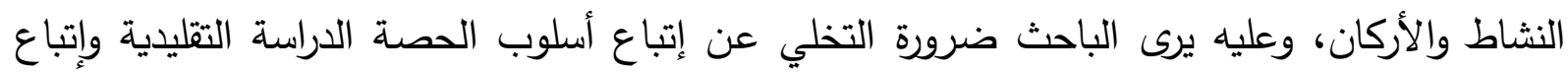
نظام اليوم المفتوح أو النشاط الحر ضمن الأركان لبناء معيار جودة التوزيع الزمني لجدول النشاطات

$$
\text { اليومية في الروضة. }
$$

4 ـ التمويل والمصروفات في رياض الأطفال:

يؤثر سوء استخدام الأموال أو نقصها سلباً على تتفيذ البرامج التربوية؛ وقد يؤدي إلى نتائج عكسية أو سلبية على جودة التعليم في الروضة، لذا يعد تدبير الأموال وتيسيرها أمراً في غاية الأهمية باعتباره مدخلا أساسياً من مدخلات النظام التربوي (عليمات، 2004). وتثير الدراسات الدتعلقة بتمويل التعليم في الوطن العربي إلى أشكال أربعة لتمويل مؤسسات رياض الأطفال، وهي: التمويل الحكومي، والتمويل التعاوني الأهلي، تمويل خاص تحت الإثراف الحكومي، والتمويل الاستثماري (مسعود، 2005)

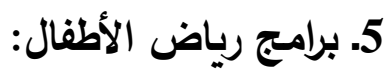
حصر بهادر (2004) برامج التربية الحديثة في رياض الأطفال في خمسة مجالات تبعا للفلسفة التي تستند اليها وذلك كالآتي: أ. مجال النشاط الحر: ويركز على النشاط الحر بحيث تُرك الحرية للطفل لاختيار النشاط بنفسه. 
ب. مجال النشاط الفكري: ويركز على التعلم الذاتي؛ إذ يتاح للطفل التعلم حسب ميوله وقدراته.

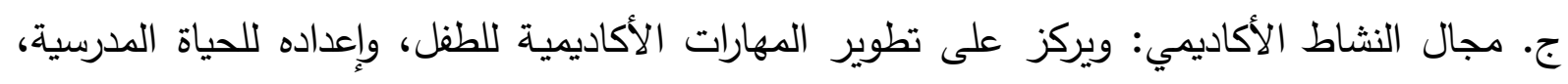

$$
\text { وهي برامج تعتمد على التكرار والتدريب أكثر من اعتمادها على اللعب. }
$$

د. مجال التعليم المفتوح: ويركز على تقسيم الأطفال في الروضة إلى مجموعات تمارس مشروعاتها المختلفة بما يتماشى مع استعدادات وإمكانات الطفل والبيئة. هـ. مجال الفعالية الأسرية: ويركز على مساندة العلاقة بين الروضة والأسرة بحيث يصبح الأهالي قادرين

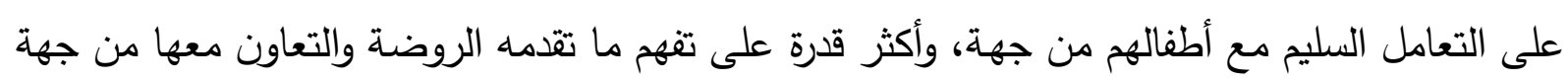
أخرى، ويتداخل مع هذا الدجال واحد أو أكثر من المجالات السابقة. 6. المباني والتجهيزات: أوردت اليونسكو (1991) والنقيب (2011) ووزارة التربية والتعليم العالي (2013) مجموعة من العناصر المتعلقة بالمباني والتجهيزات والمتمثلة في الآتي: أ. موقع الروضة: يمتاز هذا العنصر بمجموعة من الخصائص والمعايير منها الهدوء وبعده عن بن الضوضاء والضجيج مما يحمي الطفل من التلوث السمعي أو ما يسمى بتلوث البيئة بالضجيج، وكذلك ونك

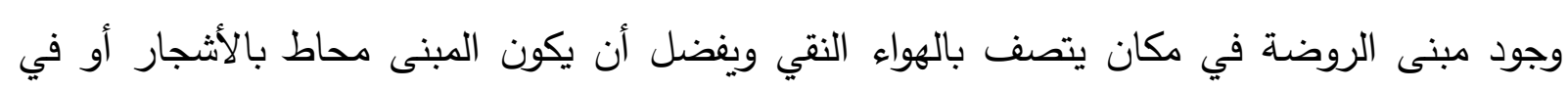

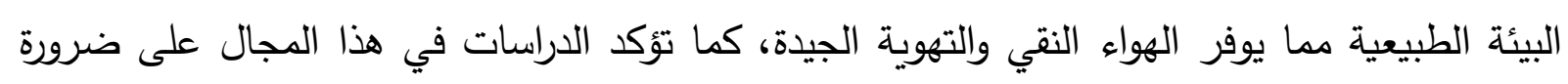

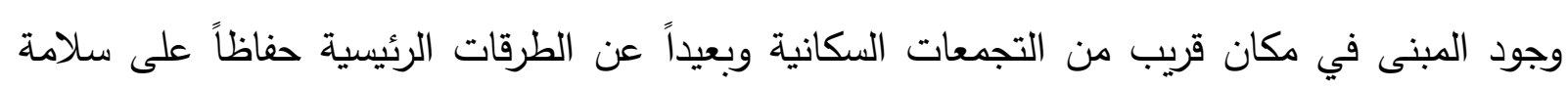

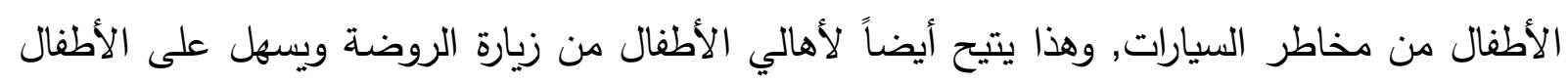
الوصول إليها دون عناء ومشقة السفر والتتقل من أماكن بعيدة. ب. مكونات مبنى الروضة: تتكون الروضة من عدة أقسام بحيث تشتمل على: (الإدارة، غرفة المربيات، ليّاء

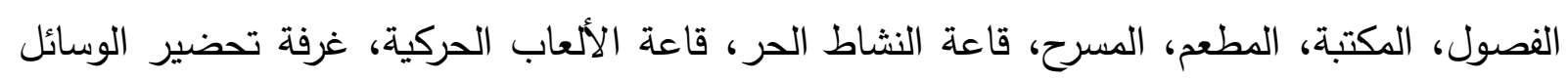

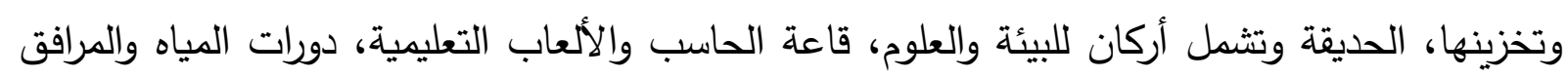

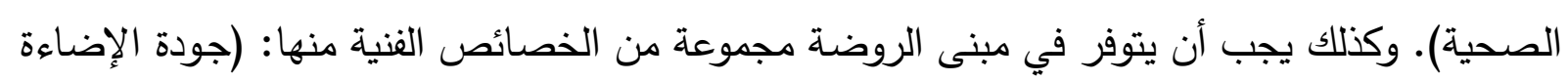

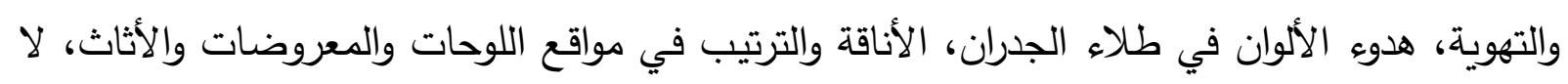

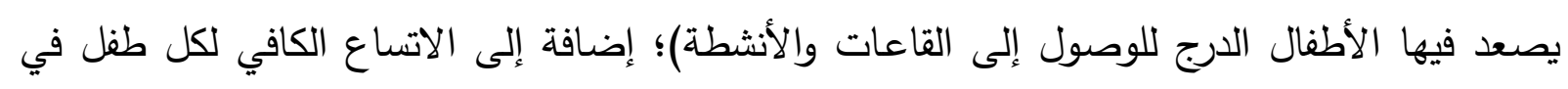

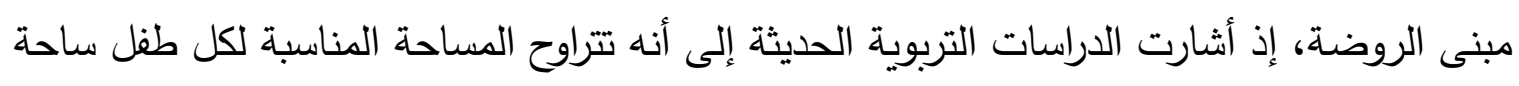
النشاط ما بين (1.5-4) أمتار، لأن هذه المساحة تزيد من فرص التربة التفاعل الاجتماعي بين الأطفال ضمن من جهة، وتسمح بحرية الحركة والنشاط للطفل من جهة أخرى. 
ج. التجهيزات والوسائل والألعاب والأثاث: بحيث تتناسب مع الخصائص النمائية للطفل وتساعد على تحقيق الدقاصد التربوية للروضة، وتراعي عوامل الأمان والسلامة للأطفال، وتكون ذات مواصفات جمالية من حيث الثكل والحجم والألوان وقابلية نقلها من مكان لآخر . 7. التقييم في رياض الأطفال: ويركز على رفع جودة الأداء في مرحلة ما قبل المدرسة من خلال تقييم أداء العاملين في الروضة من كوادر إدارية وتربوية، وتقييم مدى اكتساب الأطفال من خبرات وتطور في مجالات نموهم، وكفاية المباني والتجهيزات، وأخيراً مدى التعاون ما بين الروضة ولئه والمجتمع المحلي. وعليه، من الضروري إيجاد بيئة تربوية تراعي النواحي التربوية والثكل الجمالي الذي يتناسب مع نمو ومتطلبات الأطفال في هذه المرحلة. الدراسات السابقة:

وقد أجريت العديد من الدراسات التي تتاولت جودة البيئة التربوية في رياض الأطفال منها: هدفت دراسة (علي أحمد، 2019) إلى التعرف على الدور التربوي لمؤسسات رياض الأطفال من وجهة نظر مديرات ومربيات هذه الرياض في فلسطين، تكون مجتمع الدراسة من جميع مديرات ومربيات رياض الأطفال في محافظة سلفيت البالغ عددهم (58) مديرة، و(116) مربية، وتكونت عينة الدراسة بنسبة (100\%) من مجتمع الدراسة، واعتمدت الاستبانة كأداة للدراسة، واستخدم المنهج الوصفي المسحي الميداني كمنهج للدراسة، وتم استخدام البرنامج الإحصائي للعلوم الاجتماعية (SPSS) من أجل معالجة البيانات إحصائياً، ومن نتائج الدراسة عدم وجود فروق ذات دلالة إحصائية عند مستوى الدلالة (0.05 ) للدور التربوي لمؤسسات رياض الأطفال في فلسطين من وجهة نظر مديرات ومربيات الرياض تبعا لمتغير طبيعة العمل والتخصص، ووجود فروق ذات دلالة إحصائية عند مستوى الدلالة (0.05 = للدور التربوي لمؤسسات رياض الأطفال في فلسطين من وجهة نظر مديرات ومربيات الرياض تبعاً لمتغير المؤهل العلمي. كما أجرت وزارة التربية والتعليم في أونتاريو (Ontario Ministry of Education, 2016) دراسة هدفت إلى تقييم دور روضة الأطفال في التحصيل الدراسي للطلبة من الصفوف الأول - الثاني عشر، وقد أظهرت هذه الدراسة بأن برنامج رياض الأطفال الذي يلتحق به الأطفال والذي يستند إلى اللعب والاستقصاء لزيادة النمو المعرفي لدى الأطفال، يعد مناسبا من الناحية التتموية للطفل، وتم تقييم الطلبة وبرنامج رياض الأطفال في مدارس أونتاريو بناءً على تعليمات وزارة التربية والتعليم فيها؛ وأن لئ 
مناهج رياض الأطفال تتفق مع الدحتوى والفلسفة والهدف من البرنامج، وأظهرت الدراسة في نتائجها أن مناهج برنامج رياض الأطفال في مدارس أونتاريو تتميز بأنها قادرة على تتمية النمو المعرفي لدى الطفل،

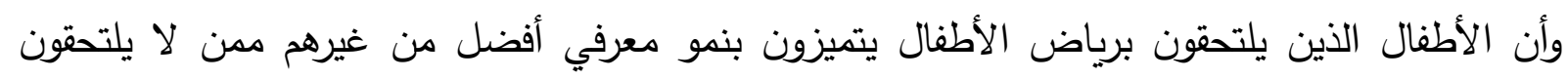
ببرنامج رياض الأطفال.

وقام حسبي (Hespe, 2014) بدراسة هدفت إلى معرفة معايير التعليم في مرحلة ما قبل المدرسة، وتقديم معلومات نظرية عنه لتطويره، وذلك لأن استخدامها بفاعلية يعتبر أمر ضروري لتنمية احتياجات الأطفال في برنامج ما قبل المدرسة لفائدته في تحصيلهم الدراسي في المدرسة، لذا يجب توفير

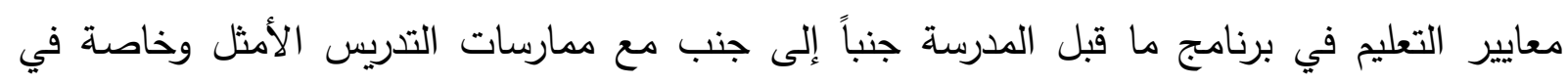

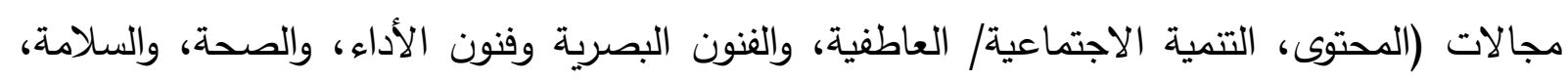
والتربية البذنية، وفنون اللغة الإنجليزية، ومقاربات التعلم، والرياضيات، والعلوم، والدراسات الاجتماعية، والأسرة، والمهارات الحياتية، والتكنولوجيا، وأظهرت الدراسة أن ممارسة وتطبيق معايير التعليم الجيد في ولئي

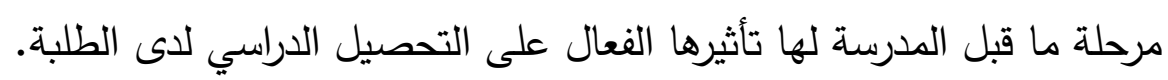
وأجرى هرش (Hirsh, 2014) دراسة هدفت إلى التعرف على المبادئ الأساسية للممارسة عالية

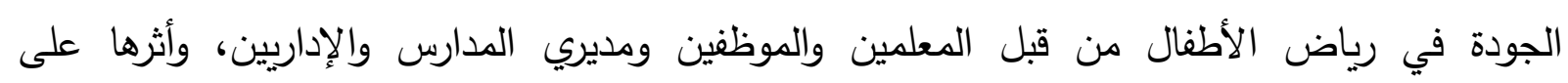
التحصيل الدراسي لطلاب الصف الأول الأساسي، وقد استخدمت هذه الدراسة الاستبانة كأداة للدراسة وقد ولدين

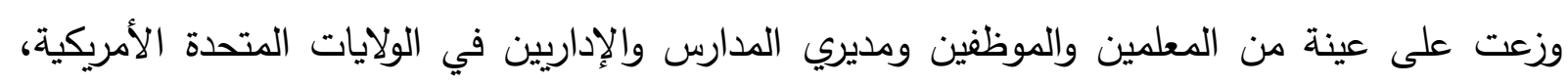
وأظهرت نتائج الدراسة وجود خلفية ومعرفة لدى المبحوثين بأفضل الممارسات لمربيات رياض الأطفال

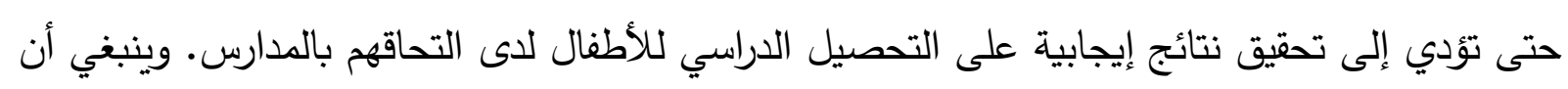
تكون هذه المبادئ الأساسية بمثابة بداية في الالتزام المستمر بالتتمية المهنية في التعليم في مرحلة الطفولة المبكرة وفي نهاية المطاف تحسين نتائج أداء الأطفال. وأجرى أحمد (2013) دراسة هدفت إلى التعرف على معايير الجودة والاعتماد في مرحلة الطفولة المبكرة، والاطلاع على تجارب بعض الدول في ذلك، إضافة الى معرفة الصعوبات التي قد تعيق تطبيق معايير الجودة والاعتماد في هذه المرحلة، وتقديم مقترح لتطبيق هذه المعايير للتغلب على تلك المعوقات. وتم استخدام المنهج الوصفي في هذه الدراسة، وتم تطبيق الاستبانة كأداة للدراسة على عينة من مديرات ومربيات رياض الأطفال ببعض مراكز محافظة أسيوط. وأسفرت نتائج الدراسة الميدانية عن موافقة أفراد العينة على وجود معوقات، وذلك بدرجة إيجابية كبيرة بنسبة وصلت إلى (90\%)، وعرضت الدراسة 
تصوراً مقترحاً لتفعيل تطبيق معايير الجودة والاعتماد في مرحلة رياض الأطفال في مصر، والتغلب على تلك الصعوبات. كما أجرى فايد (2013) دراسة هدفت إلى معرفة واقع تطبيق إدارة الجودة الثاملة في رياض الأطفال، وضبط الصعوبات التي تواجه عملية التطبيق، وكذلك تقديم تصور مقترح لمواجهة تلك المعوقات، وتم استخدام المنهج الوصفي التحليلي في إجراء الدراسة، وتم اعتماد الدقابلات المفتوحة والاستبانة كأداتين للدراسة، وتم تطبيقهما على عينة من مديرات ومربيات رياض الأطفال التابعة للددارس الحكومية والخاصة في محافظات الفيوم وبني سويف والقاهرة والإسكندرية، ومن أهم نتائج الدراسة: وجود عدد كبير من الصعوبات والمعوقات التي أدت إلى عدم إمكانية تطبيق إدارة الجودة الثاملة في رياض

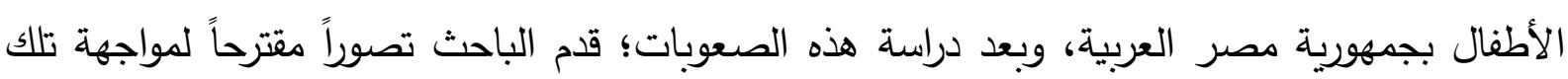
الصعوبات من خلال المحاور التالية: أهداف الروضة، طفل الروضة، مربية الروضة، البرامج التربوية والمنهاج، مبنى الروضة وتجهيزاته، التمويل والنفقات، مشاركة المجتمع، وإدارة الروضة، بيئة الروضة والجو التربوي، ضمان الجودة والمحاسبة. وهدفت دراسة النقيب (2011) إلى الوقوف على الثروط التي يجب توافرها في مباني رياض الأطفال، بما يتناسب مع خصائص نمو الطفل وتلبية حاجاته النمائية، ومعرفة أهم المشكلات التي تعاني منها المباني، وتنبيه القائمين على تصميم مباني المؤسسات التعليمية غلى ضرورة إعادة النظر فيها وتنفيذها وفق الشروط المناسبة. تم استخدام المنهج الوصفي، تكونت العينة من (81) إدارة تعليمية تابعة لرياض الأطفال بمحافظة الإسكندرية، وتمّ التوصل إلى وضع تصور مقترح تتحدد أهدافه بالآتي: 1) التأكيد على أهمية إيجاد بيئات تربوية تجمع بين تلبية النواحي التربوية ومراعاة الثكل الجمالي، بما يتناسب مع متطلبات نمو واحتياجات أطفال هذه المرحلة. 2) إيجاد إدارة خاصة للإشراف على تصميم، وتتفيذ وتجهيز وصيانة مباني رياض الأطفال، والتي تختلف شكلا ومضمونا عن سائر مباني المؤسسات التربوية الأخرى. 3) الاستفادة من مباني رياض الأطفال القائمة بالفعل، وإعادة هيكلتها لكي تتناسب مع لئس طبيعة أطفال هذه المرحلة وتلبي احتياجاتهر. وهدفت صاصيلا (2010) في دراستها إلى رصد واقع البيئة التربوية في رياض الأطفال في مدينة دمشق، ومن ثم تتجه إلى وضع تصور للبيئة التربوية المتعلقة ببناء الروضة وتجهيزاتها وفقاً لمعايير الجودة المطلوبة، وذلك بالاعتماد على متطلبات برامج التعليم المفتوح وبرامج الأثشة وبرامج الأركان. واعتُمد على المنهج الوصفي التحليلي لرصد الواقع ولتحديد معايير جودة البناء والتجهيزات، 
واستخدت الاستبانة كأداة للدراسة، وتم تطبيقها على عينة مكونة من (124) مربية يعملن في (61) روضة خاصة في مدينة دمشق. ومن نتائج الدراسة التي أظهرتها ضعف مناسبة مواصفات بناء الروضة وتجهيزاتها لمعايير الجودة التربوية في رياض الأطفال، كما اقترح البحث معايير لجودة البيئة التربوية ومتطلبات البناء والتجهيزات استندت إلى مراعاة خصائص طفل الروضة والأهداف التربوية لرياض لهاض الأطفال ومعايير الصحة والسلامة، إضافة إلى المعايير الجمالية والاقتصادية. وفي دراسة أجرتها أبو دقة وآخرون (2007) هدفت إلى تشخيص جودة التعليم في رياض الأطفال في قطاع غزة؛ من خلال التعرف على واقع رياض الأطفال في محافظات غزة من حيث جودة التعليم وخاصة في المجالات التالية: المنهج، كفاءة المربيات، المواد التربوية المستخدمة في الرياض، مشاركة

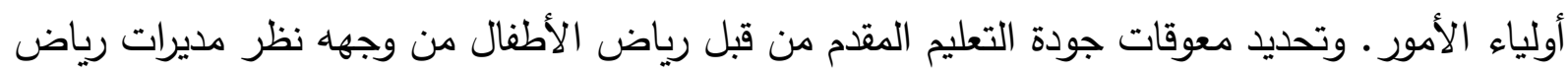
الأطفال والمربيات. تكون مجتمع الدراسة من (122) روضة من رياض الأطفال في قطاع غزة، اختير منها عشوائيا (54) روضة موزعة جغرافياً في محافظات قطاع غزة كعينة طبقية للدراسة، اعتُمدت الاستبانة والمقابلة كأدوات للدراسة. وقد بينت نتائج الدراسة وجود العديد من المعوقات والحاجة إلى العديد من التدخلات في مجالات: المنهج، كفاءة المربيات، المواد التربوية، مشاركة أولياء الأمور؛ إذ بينت النتائج استخدام نظام الصف التقليدي (نظام الحصص)، وهيمنة البعدين الاجتماعي والمعرفي كأهداف رئيسه للروضة من وجهه نظر المديرات والمربيات وأولياء الأمور، أما بالنسبة لكفاءة المربيات فقد بينت النتائج أن جميعهن لديهن شهادة الثانوية العامة وثلث أفراد العينة لديهن مؤهل جامعي، وبالنسبة للمواد التربوية فقد بينت النتائج أنها غير متوفرة بشكل كاف في رياض الأطفال. أما بالنسبة لمشاركة أولياء

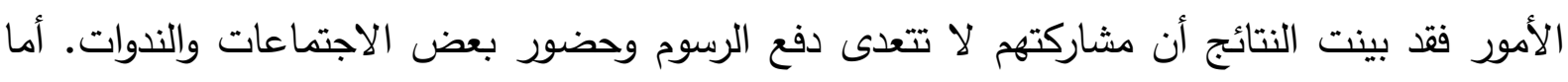
المعوقات من وجهه نظر المربيات والمديرات فهي كثيرة أهها تلك المتعلقة بعدم دفع الرسوم، والمشاكل السلوكية من قبل الأطفال، وضعف تفاعل الأهالي إلى جانب تدني راتب المربيات وقلة خبرتهن في مجال

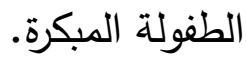

ويسعى البحث الحالي إلى تحديد معوقات تطبيق جودة البيئة التربوية في رياض الأطفال الفلسطينية من وجهة نظر مديرات ومربيات الرياض، واقتراح مجموعة من التوصيات تسهم في تجويد البيئة التربوية في رياض الأطفال بما يتتاسب والحاجات النمائية للطفل من جهة، والمعايير الجمالية والاقتصادية والصحية من جهة أخرى. كما يتاول دراسة واقع البيئة التربوية في رياض الأطفال الفلسطينية، من حيث المباني والتجهيزات، والتحقق من مدى مقاربة هذا الواقع مع جودة البيئة التربوية. 
تشتمل على وصف كل من منهج الدراسة ومجتمع الدراسة وعينتها إضافة إلى وصف خطوات بناء أداة الدراسة وإجراءات تطبيقها، والتحليلات الإحصائية التي تمت. منهج الاراسة:

استخدم الباحث المنهج الوصفي المسحي الميداني نظراً لملاعمته لأغراض الدراسة.

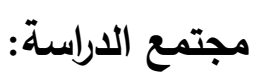

تكون مجتمع الدراسة من جميع مديرات ومربيات رياض الأطفال المرخصة من وزارة التربية والتعليم العالي في محافظة سلفيت للعام الدراسي (2019/2018) والبالغ عددهن (58) مديرة و (116) مربية يعملن في (58) روضة. عينة الدراسة: شملت عينة الدراسة على (174) مديرة ومربية رياض أطفال بنسبة (100\%) من مجتمع الدراسة للمديرات والمربيات، حيث توزعت العينة على النحو الاتي: توزيع العينة حسب متغير طبيعة العمل وبينه الجدول (1).

جدول (1)

توزيع العينة حسب متغير طبيعة العمل

\begin{tabular}{|c|c|c|}
\hline النسبة \% & العدد & طبيعة العمل \\
\hline$\% 33.3$ & 58 & مديرة \\
\hline$\% 66.7$ & 116 & مربية \\
\hline$\% 100$ & 174 & المجموع \\
\hline
\end{tabular}

جدول (2)

توزيع العينة (للمديرات وإلمربيات) حسب متغيرات الدراسة

\begin{tabular}{|c|c|c|c|c|c|}
\hline النسبة \% & عدد المربيات & النسبة \% & عدد المديرات & المتغير & المتغير \\
\hline$\% 11.2$ & 13 & $\% 5.2$ & 3 & توجيهي & \multirow{3}{*}{ المؤهل العلمي } \\
\hline$\% 16.4$ & 19 & $\% 15.5$ & 9 & دبلوم (معهد) & \\
\hline$\% 72.4$ & 84 & $\% 79.3$ & 46 & بكالوريوس فأعلى & \\
\hline$\% 28.4$ & 33 & $\% 34.5$ & 20 & أقل من 6 سنوات & \multirow{3}{*}{ سنوات الخبرة } \\
\hline$\% 46.6$ & 54 & $\% 43.1$ & 25 & من 6-10 سنوات & \\
\hline$\% 25$ & 29 & $\% 22.4$ & 13 & 11 سنة فأكثر & \\
\hline$\% 19$ & 22 & $\% 13.8$ & 8 & عزباء & \multirow{4}{*}{ الحالة الاجتماعية } \\
\hline$\% 70.7$ & 82 & $\% 67.2$ & 39 & متزوجة & \\
\hline$\% 6$ & 7 & $\% 8.6$ & 5 & مطلقة & \\
\hline$\% 4,3$ & 5 & $\% 10.3$ & 6 & أرملة & \\
\hline
\end{tabular}


قام الباحث بإعداد أداة الدراسة (الاستبانة) وتطويرها بنفسه بعد الاطلاع على المعلومات المتصلة بها والدراسات ذات العلاقة. وقد اعتمد الباحث على هذه الاستبانة في التوصل إلى نتائج الدراسة الحالية. وبلغ مجموع الفقرات فيها (36) فقرة موزعة على مجالي الدراسة (منها (18) فقرة لمجال المعوقات المادية، و(18) فقرة لمجال المعوقات الفنية). وقد روعي في بناء الاستبانة مدى مناسبتها للعينة من حيث الصياغة اللغوية، ووضوح ما تسأل عنه الفقرات. وقد تم تدريج الاستبانة بشكل ثنائي حسب نظام (ليكرت) الثنائي؛ إذ وزعت الدرجات على الفقرات كالآتي:

$$
\text { - نعم (2 درجة). }
$$

ومن أجل تفسير النتائج، اعتمدت المتوسطات الحسابية المعتمدة والخاصة بالاستجابة على الفقرات

- (80\%) - (من 70\%-79.99\%) درجة أثر كبيرة. - (من 60\%-69.99\%) درجة أثر متوسطة. - (من 50\%-59.99\%) درجة أثر قليلة.

$$
\text { - (أقل من 50\%) درجة أثر قليلة جداً. }
$$

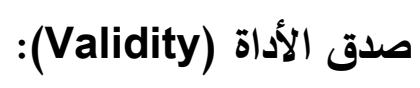

تم عرض الأداة بعد بنائها من قبل الباحث على عدد من المتخصصين (أساتذة من قسم رياض الأطفال في جامعة النجاح الوطنية، ومشرفات رياض الأطفال في وزارة التربية والتعليم ومديرياتها، ومجموعة من المديرات والمربيات العاملات في رياض الأطفال). وقام الباحث بناءً على رأي المحكمين

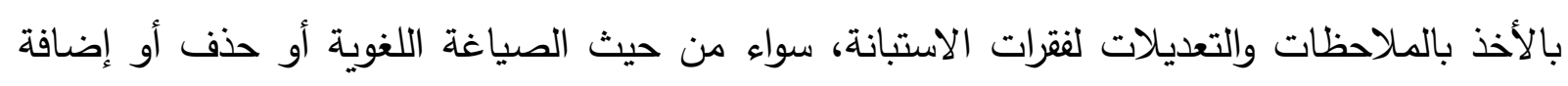

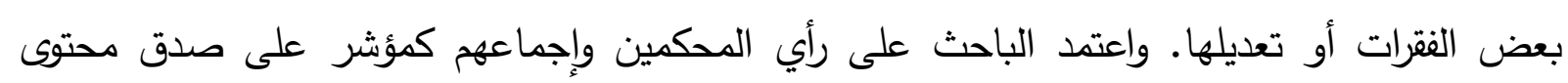

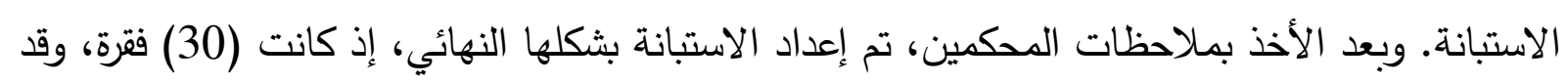
أصبح عدد فقراتها (36) فقرة. ومن التعديلات التي نفذها الباحث بناء على ملاحظات المحكمين: إضافة ثلاث فقرات لكل مجال، وتعديل لغوي لعدد آخر من الفقرات. 
ثبات الأداة: بعد تطبيق أداة الدراسة على العينة، تم حساب معامل الثبات للأداة عن طريق استخدام معادلة (كرونباخ ألفا) للاتساق الداخلي، حيث بلغت قيمة معامل الثبات (0.888)، وهذه القيمة مقبولة لمعامل الاتساق الداخلي في حدود أغراض هذه الدراسة وطبيعتها. إجراءات التطبيق وخطواته: قام الباحث بإجراء الدراسة وفق الإجراءات والخطوات الآتية: 1- الاطلاع على المعلومات والدراسات السابقة المتعلقة بموضوع الدراسة. 2- بناء وتصميم أداة الدراسة من جانب الباحث، وصياغة فقراتها. 3- إيجاد الصدق للأداة من خلال عرضها على المحكمين المتخصصين. 4- توزيع الأداة على مجتمع الدراسة، وأصبح العدد النهائي القابل للتحليل (174) استبانة. 5- 5 - 5ساب معامل الثبات لأداة الدراسة. 6- تحليل البيانات من خلال الحاسوب. أساليب المعالجة الإحصائية:

تم استخدام البرنامج الإحصائي للعلوم الاجتماعية (SPSS) من أجل معالجة البيانات إحصائياً، وذلك باستخدام المعالجات الإحصائية الآتية: 1. المتوسطات الحسابية والإنحرافات المعيارية والنسب المئوية لاستجابات أفراد عينة الدراسة على الاستبانة ككل وعلى كل فقرة من فقراتها. 2. اختبار (ت) للمجموعتين المستقلتين (Independent T-test). 3. تحليل التباين الأحادي (One Way ANOVA). 4. معادلة (كرونباخ ألفا) لحساب الثبات. 5. اختبار كرونباخ ألفا لإيجاد الفروق بين المستويات. نتائج الدراسة ومناقشتها: هدفت الدراسة الحالية إلى التعرف على "معوقات تطبيق جودة البيئة التربوية في رياض الأطفال

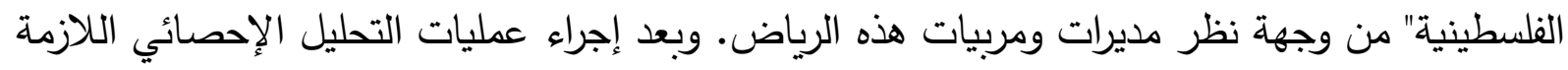
وتطبيق إجراءات الدراسة على استبانة أعدها الباحث مكونة من (36) فقرة موزعة على مجات مجالين، فقد تم

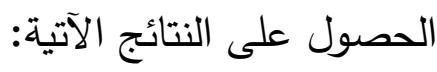
النتائج المتعلقة بالسؤال الأول للاراسة والذي ينص: "ما معوقات تطبيق جودة البيئة التربوية في رياض الأطفال من وجهة نظر مديرات ومربيات رياض الأطفال في فلسطين حسب مجالي (المعوقات المادية، 
معوقات تطبيق جودة البيئة التربوية في رياض الأطفال الفلسطينية ... نافز ״علي أحمد“"

للإجابة على السؤال، استخدم الباحث المتوسطات الحسابية لكل فقرة وعلى الدرجة الكلية للأداة عند العينة، والجدول (3) يبين ذلك.

\section{جدول (3)}

التكرار والنسبة المئوية للاستجابة حسب نوع الاستجابة على الفقرة والدارجة الكلية لكل مجال ولجميع فقرات الأداة

\begin{tabular}{|c|c|c|c|}
\hline 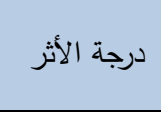 & نسبة & المتوسط الحسابي & 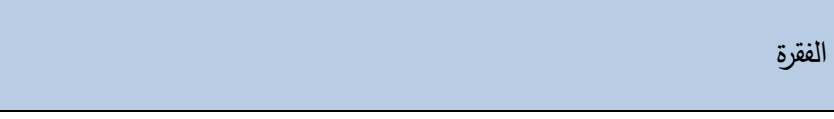 \\
\hline \multicolumn{4}{|c|}{ المجال الأول : المعيقات المادية } \\
\hline كبيرة جدا & $\% 97.37$ & 1.947 & 1. عدم كفاية الموارد المالية المتوافرة لشراء الوسائل والالعاب. \\
\hline كبيرة جدا & $\% 97.37$ & 1.947 & 2. عدم كفاية الالعاب التعليمية. \\
\hline كبيرة جدا & $\% 95.49$ & 1.910 & 3. عدم كفاية الوسائل التعليمية. \\
\hline كبيرة جدا & $\% 90.23$ & 1.805 & 4. عدم توافر مكتبة. \\
\hline كبيرة جدا & $\% 84.21$ & 1.684 & 5. عدم توافر ساحات وملاعب. \\
\hline كبيرة جدا & $\% 84.59$ & 1.692 & 6. عدم كفاية أقسام المبنى لتحقيق الاهداف النمائية للطفل. \\
\hline كبيرة جدا & $\% 86.84$ & 1.737 & 7. عدم توافر أدلة عمل ترشد المعلمة الى اساليب تنفيذ بعض الخبرات. \\
\hline كبيرة جدا & $\% 89.10$ & 1.782 & 8. عدم توافر الكهرباء. \\
\hline كبيرة جدا & $\% 93.61$ & 1.872 & 9. عدم توافر أجهزة حاسوب. \\
\hline كبيرة جدا & $\% 88.35$ & 1.767 & 10. عدم تتاسب المشربيات مع عدد الاطفال. \\
\hline كبيرة جدا & $\% 90.23$ & 1.805 & 11. عدم تناسب المرافق والتجهيزات مع ذوي الحاجات الخاصة. \\
\hline كبيرة جدا & $\% 90.60$ & 1.812 & 12. عدم تتاسب الحمامات مع عدد الاطفال. \\
\hline 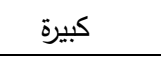 & $\% 79.32$ & 1.586 & 13. عدم وجود أذنة. \\
\hline 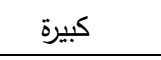 & $\% 76.69$ & 1.534 & 14. عدم توافر وسائل الاسعاف الاولي. \\
\hline كبيرة جدا & $\% 82.33$ & 1.647 & 15. عدم توافر الوسائل السمعية والمرئية (تلفزيون، راديو ، مسجل). \\
\hline كبيرة جدا & $\% 83.08$ & 1.662 & 16. عدم وجود باص أو وسيلة نقل للأطفال. \\
\hline كبيرة جدا & $\% 88.35$ & 1.767 & 17 ـ قلة رواتب المربيات. \\
\hline كبيرة جدا & $\% 84.59$ & 1.692 & 18. عدم وجود انترنت. \\
\hline كبيرة جدا & $\% 87.91$ & 1.758 & مجموع الاستجابات للمجال الأول \\
\hline \multicolumn{4}{|c|}{ المجال الثاني: المعيقات الفنية } \\
\hline كبيرة جدا & $87.22 \%$ & 1.744 & 1. عدم تتاسب المؤهلات العلمية. \\
\hline 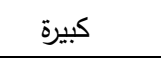 & $78.95 \%$ & 1.579 & 2. عدم توفر مرشدة. \\
\hline 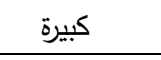 & $78.20 \%$ & 1.564 & 3. ضعف قدرة المربيات على استخدام الحاسوب. \\
\hline كبيرة جدا & $80.45 \%$ & 1.609 & 4. عدم تتاسب الوسائل والتجهيزات مع اساليب التعلم التعاوني في الروضة. \\
\hline كبيرة جدا & $83.83 \%$ & 1.677 & 5. عدم تتاسب تنظيم بناء الروضة مع نظام الأركان وبرامج التعليم المفتوح. \\
\hline كبيرة جدا & $83.83 \%$ & 1.677 & 6. عدم توافر المؤهل المسلكي لدى المربيات. . \\
\hline كبيرة جدا & $84.21 \%$ & 1.684 & 7. عدم توافر أدلة عمل ترشد المعلمة إلى أساليب تنفيذ بعض الخبرات. \\
\hline كبيرة جدا & $84.21 \%$ & 1.684 & 8. كثرة عدد الاطفال في غرفة النشاط. \\
\hline كبيرة جدا & $85.71 \%$ & 1.714 & 9. عدم كفاية الدورات التدريبية التي تشارك فيها الروضة. \\
\hline كبيرة جدا & $86.09 \%$ & 1.722 & 10. عدم تشكيل مجلس الامهات. \\
\hline كبيرة جدا & $85.34 \%$ & 1.707 & 11. ضعف مهارات التواصل لإدارة الروضة في توفير بيئة إنسانية ميسرة. \\
\hline
\end{tabular}


مجلة كلية فلسطين التقنية للأبحاث والدراسات 2020، المجلد السابع

\begin{tabular}{|c|c|c|c|}
\hline كبيرة جدا & $90.23 \%$ & 1.805 & 12. ضعف التعاون ما بين الأهالي والروضة في تحقيق أهداف المنهاج. \\
\hline كبيرة جدا & $84.21 \%$ & 1.684 & 13. عدم التعاون والتتسيق ما بين الإدارة والمعلمات. \\
\hline كبيرة جدا & $83.83 \%$ & 1.677 & 14. ضعف الإشراف التربوي. \\
\hline كبيرة جدا & $89.85 \%$ & 1.797 & 15. عدم وجود أنثطة تنافسية بين الرياض. \\
\hline كبيرة جدا & $93.23 \%$ & 1.865 & 16. التركيز على التعليم على حساب المهارات. \\
\hline كبيرة جدا & $91.73 \%$ & 1.835 & 17 ل قلة الرحلات الترفيهية. \\
\hline كبيرة جدا & $91.35 \%$ & 1.827 & 18. قلة الانشطة الترفيهية (حفلات، مسابقات) \\
\hline كبيرة جدا & $85.69 \%$ & 1.714 & مجموع الاستجابات للمجال الثاني \\
\hline كبيرة جدا & $86.80 \%$ & 1.736007 & لملأداة \\
\hline
\end{tabular}

نتائج تحليل المجال الأول: المعوقات المادية:

بالنسبة للدجال الأول؛ يُظهر الجدول السابق (3) أن متوسط الاستجابة (كبيرة جداً) على الفقرات

(1، 2، 3، 4، 5، 6، 7، 8، 9، 10، 11، 12، 15، 16، 16، 17، 18، 18، وتراوح متوسط الاستجابة عليها

من قبل العينة بين (80.45\%-97.37\%)، وكانت الاستجابة (كبيرة) على الفقرتين (13، 14)، وتراوح متوسط الاستجابة عليهما من قبل العينة بين (76.69\%-79.32\%). ويتضح أن متوسط الاستجابة من قبل العينة بالموافقة (نعم) للمجال الأول والذي يتحدث عن المعوقات المادية (كبيرة جداً)، وبلغت (87.91\%) على الدرجة الكلية لجميع فقرات المجال. إن درجة الأثر (كبيرة جداً) تعني أن مضمون

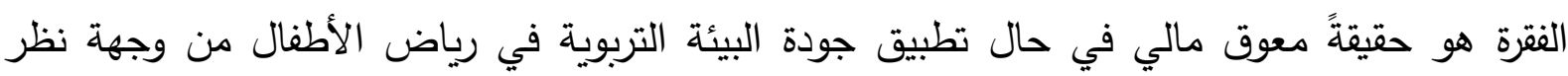

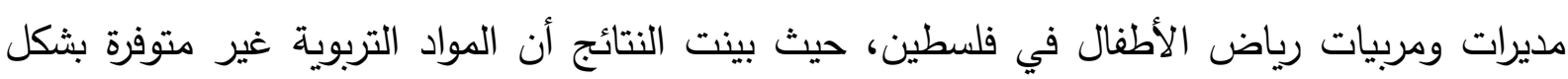
كافٍ في رياض الأطفال، ويعتبر المال عنصر أساسي في توفير ما يلزم المربيات من وسائل تعليمية

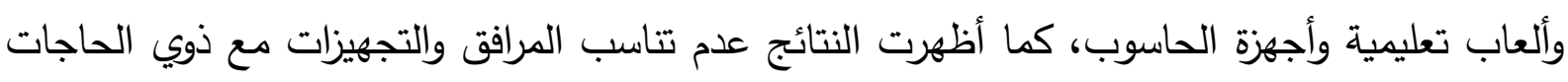
الخاصة، وعدم تتاسب الحمامات مع عدد الأطفال؛ مما يؤكد على وجود قصور في مواصفات بناء الروضة وتجهيزاتها لمعايير الجودة التربوية في رياض الأطفال. ويعتقد الباحث أن سبب الضعف المادي يعود إلى أن الإنفاق وتغطية مصروفات الروضة في فلسطين يعتمد بشكل أساسي على مدخولات الروضة لئة

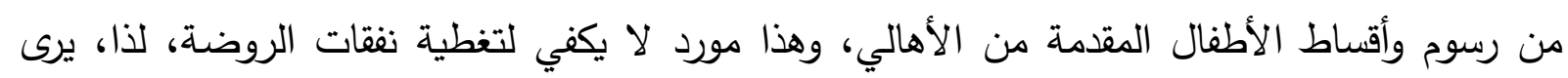

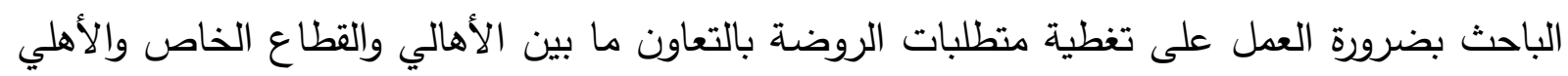
والحكومي، وتتقق هذه النتيجة مع دراسة (صاصيلا، 2010؛ فايد، 2013) إذ تبين وجود ضعف في عنصر المال في الرياض اللازم لتغطية مستلزمات الروضة؛ وتتفق هذه النتيجة أيضا مع ما أظهرته أبو دقه في دراستها (2007) إذ بينت النتائج أن المواد التربوية غير متوفرة بشكل كاف في رياض الأطفال. 


\section{نتائج تحليل المجال الثاني: المعوقات الفنية:}

أما بالنسبة للمجال الثاني والذي يتعلق بالمعوقات الفنية، فنجد أن متوسط الاستجابة (كبيرة جداً) على الفقرات (1. 4، 5، 6، 7، 8، 9، 10، 11، 12، 13، 14، 15، 16، 17، 18)، وتراوح متوسط الاستجابة عليها من قبل العينة بين (82.33\%-93.23\%)، وكانت الاستجابة (كبيرة) على الفقرتين (2، 3)، وتراوح متوسط الاستجابة عليهما من قبل العينة بين (78.20\%-78.95\%). ويتضح أن متوسط الاستجابة من قبل العينة بالموافقة (نعم) للمجال الثاني والذي يتحدث عن المعوقات الفنية (كبيرة جداً)، وبلغت (85.69\%) على الدرجة الكلية لجميع فقرات المجال. وهذا يدلل على أن ما ورد في هذا المجال من فقرات تثكل معوقات فنية والتي تواجه تطبيق جودة البيئة التربوية في رياض الأطفال من وجهة نظر مديرات ومربيات رياض الأطفال في فلسطين، ويرى الباحث أن هذا يعود إلى عدم توفر مربيات مؤهلات للعمل في رياض الأطفال، وإلى قلة دراية المديرات ومعرفتهن للبرامج التربوية المناسبة والحديثة، وضعف التعاون ما بين الأهالي والروضة في تحقيق أهداف الروضة وأنشطتها، وتتقق هذه النتيجة مع ما توصلت إليه دراسات كل من: (الشريف، 2006)؛ ابو دقة، 2007؛ صاصيلا، 2010؛ فايد، 2013)، فقد بينت نتائج هذه الدراسات أن مشاركة أولياء الأمور لا تتعدى دفع الرسوم وحضور بعض الاجتماعات والندوات. وقد يعود عدم تنفيذ أنثطة الروضة بشكل أساسي لعدم وجود مؤسسة أو جهة تتظم وترعى مثل هذه النشاطات، ولهذا يرى الباحث أن تهم التربية والتعليم بالتخطيط وتنظيم ورعاية مثل هذه النشاطات بالتعاون مع المؤسسات الأهلية ومؤسسات المجتمع الدذني. ومن معيقات تحقيق أهداف الروضة ضعف تأهيل المديرات والمربيات؛ وهذا يستدعي العمل على تأهيلهن من خلال عقد الدورات التدريبية ووش العمل في مجال تجويد البيئة التربوية وتثجيع المربيات وتقديم التسهيلات للحصول على المؤهل المسلكي للعمل في رياض الأطفال. وبشكل عام وحسب ما ظهر من الجدول السابق (3)، فإن متوسط الاستجابة للمعوقات التي تواجه تطبيق جودة البيئة التربوية في رياض الأطفال من وجهة نظر مديرات ومربيات رياض الأطفال في

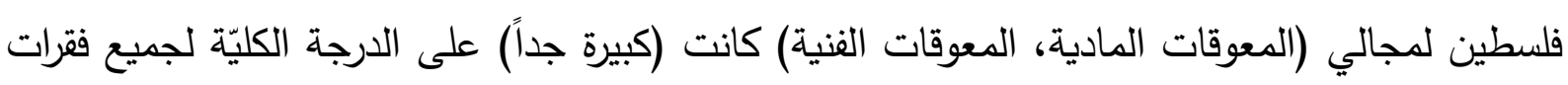
الأداة؛ إذ بلغت نسبة الاستجابة عليها من قبل العينة بالموافقة (نعم) (86.80\%) على الدرجة الكلية

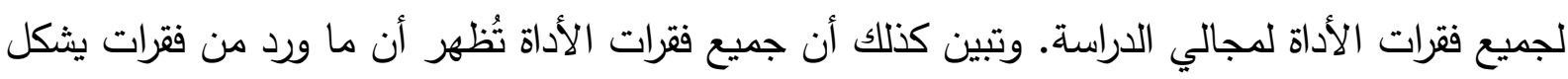
عائقا يواجه تطبيق جودة البيئة التربوية في رياض الأطفال من وجهة نظر مديرات ومربيات رياض الأطفال قي فلسطين؛ لكن باختلاف نسبة درجة الاستجابة لكل فقرة من فقرات الاداة. وتتفق هذه النتيجة 
مع توصلت إليه دراسة صاصيلا (2010)، إذ بينت ضعف مناسبة مواصفات بناء الروضة وتجهيزاتها لمعايير الجودة التربوية في رياض الأطفال، ودراسة أحمد (2013)، أظهرت موافقة أفراد عينة الدراسة الكلي للدراسة على وجود معوقات عند تطبيق معايير الجودة والاعتماد بمرحلة رياض الأطفال الواردة بمحاور الدراسة المختلفة، ودراسة فايد (2013)، إذ بينت وجود مجموعة كبيرة من الإثكالات والمعوقات حالت دون تطبيق إدارة الجودة الثاملة بمؤسسات رياض الأطفال بجمهورية مصر العربية، ودراسة الثال وعمارة (2009) إذ أشارت الى العديد من المعوقات والصعوبات التي تعيق تطبيق ضمان الجودة والاعتماد. ودراسة ابو دقة وآخرون (2007) إذ بينت الحاجة إلى العديد من التدخلات في مجالات: المنهج، كفاءة المربيات، المواد التربوية، مشاركة أولياء الأمور وكذلك وجود العديد من المعوقات. النتائج المتعلقة بالسؤال الثاني والذي ينص: "هل توجد فروق ذات دلالة إحصائية لمعوقات تطبيق جودة البيئة التربوية في رياض الأطفال من وجهة نظر مديرات ومربيات الرياض في فلسطين تعزى لمتغيرات الدراسة: طبيعة العمل، المؤهل العلمي، وسنوات الخدمة، والحالة الاجتماعية؟"

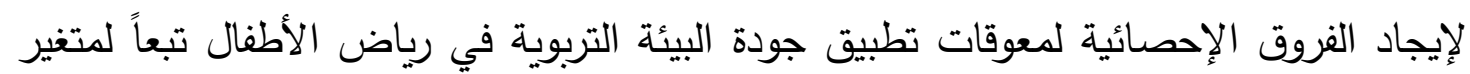
طبيعة العمل، استخدم الباحث اختبار (ت) (T-test) لمجموعتين مستقلتين لدلالة الفروق على الدرجة الكلية للأداة. كما يوضحه الجدول (4).

جلول (4) (4) (4)

إختبار (ت) (t-test) لمجموعتين مستقلتين لالالة الفروق على الارجة الكلية للأداة تبعا لمتفير طبيعة العمل

\begin{tabular}{|c|c|c|c|c|c|c|}
\hline \multicolumn{6}{|c|}{ طبيعة العمل } & \multirow{3}{*}{ الدرجة الكلية للمجالات } \\
\hline \multirow[b]{2}{*}{ الدلالة " } & \multirow{2}{*}{ (ت) } & \multicolumn{2}{|c|}{ مربية } & \multicolumn{2}{|c|}{ مديرة } & \\
\hline & & الإنحراف & المتوسط & الإنحراف & المتوسط & \\
\hline 0.21 & -1.25 & 0.17 & 0.26 & 0.18 & 0.22 & المعوقات المادية \\
\hline 0.27 & -1.11 & 0.20 & 0.30 & 0.22 & 0.26 & المعوقات الفنية \\
\hline 0.11 & -1.60 & 0.13 & 0.28 & 0.16 & 0.24 & الدرجة الكلية للأداة \\
\hline
\end{tabular}

يتضح من الجدول (4) السابق عدم وجود فروق ذات دلالة إحصائية على الدرجة الكلية للأداة تعزى لمتغير طبيعة العمل، إذ بلغت مستوى الدلالة (0.21) لهجال المعوقات المادية؛ وبلغت (0.27) لدجال المعوقات الفنية؛ وبلغت (0.11) للدرجة الكلية للأداة وجميعها أكبر من (0.05). أي لا يوجد إختلاف في رأي مديرات ومربيات رياض الأطفال في فلسطين حول معوقات تطبيق جودة البيئة التربوية في رياض الأطفال. وهذا يؤكد تقارب توجهات مديرات ومربيات رياض الأطفال في فلسطين على فقرات مجالي الدراسة وجميع فقرات الأداة، ويعزو الباحث هذه النتيجة إلى وعي مديرات ومربيات رياض الأطفال 
لمعوقات تطبيق جودة البيئة التربوية في رياض الأطفال في فلسطين. وتتفق هذه النتيجة مع دراسات كل من: (أحمد، 2013؛ فايد، 2013؛ صاصيلا، 2010؛ أبو دقة وآخرون، 2007) إذ بينت عدم وجود فروق بين المديرات والمربيات على وجود عدد كبير من الصعوبات والمعوقات التي أدت إلى عدم إمكانية تطبيق إدارة الجودة الثاملة في رياض الأطفال.

ولإيجاد الفروق الإحصائية لمعوقات تطبيق جودة البيئة التربوية في رياض الأطفال تبعاً لمتغير المؤهل العلمي، استخدم الباحث اختبار (ت) (T-test) لمجموعتين مستقلتين لدلالة الفروق على الدرجة الكلية للأداة. كما يوضحه الجدول (5).

جدول (5)

المتوسطات الحسابية للارجة الكلية للمجالين والدرجة الكلية تبعاً لمتغير المؤهل العلمي

\begin{tabular}{|c|c|c|c|}
\hline بكالوريوس فأعلى & 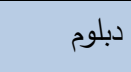 & توجيهي & المجالات \\
\hline 0.36 & 0.11 & 0.61 & المعوقات المادية \\
\hline 0.26 & 0.34 & 0.11 & المعوقات الفنية \\
\hline 0.21 & 0.34 & 0.36 & الدرجة الكلية \\
\hline
\end{tabular}

ولاستخراج دلالة الفروق للدرجة الكلية للمجالين والدرجة الكلية للأداة تبعاً لمتغير المؤهل العلمي عند العينة، تم استخدام تحليل التباين الأحادي (ANOVA). والجدول(6) يبين ذلك. جدول (6) نتائج تحليل التباين الأحادي (ANOVA) للمجالين والدرجة الكلية تبعاً لمتغير المؤهل العلمي

\begin{tabular}{|c|c|c|c|c|c|c|}
\hline مستوى & ف & متوسط المربعات & درجات & المربعات & مصدر التباين & المجالات \\
\hline \multirow{3}{*}{0.00} & \multirow{3}{*}{45.58} & 0.84 & 2 & 1.69 & بين المجموعات & \multirow[t]{3}{*}{ المعوقات المادية } \\
\hline & & \multirow[t]{2}{*}{0.02} & 171 & 2.41 & داخل المجموعات & \\
\hline & & & 172 & 4.09 & المجموع & \\
\hline \multirow{3}{*}{0.03} & \multirow{3}{*}{3.81} & 0.16 & 2 & 0.32 & بين المجموعات & \multirow[t]{3}{*}{ المعوقات الفنية } \\
\hline & & \multirow[t]{2}{*}{0.04} & 171 & 5.53 & داخل المجموعات & \\
\hline & & & 173 & 5.86 & المجموع & \\
\hline \multirow{3}{*}{0.00} & \multirow{3}{*}{16.25} & 0.27 & 2 & 0.54 & بين المجموعات & \multirow[t]{3}{*}{ جميع الفقرات } \\
\hline & & \multirow[t]{2}{*}{0.02} & 171 & 2.14 & داخل المجموعات & \\
\hline & & & 173 & 2.68 & المجموع & \\
\hline
\end{tabular}

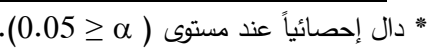

يتضح من الجدول (6) السابق وجود فروق ذات دلالة إحصائية لمعوقات تطبيق جودة البيئة التربوية في رياض الأطفال في فلسطين حسب مجالي (المعوقات المادية، المعوقات الفنية) والدرجة الكلية للأداة تعزى لمتغير المؤهل العلمي، ويتضح أن هذه الفروق كانت لصالح من يحملون شهادة الثانوية 
العامة (توجيهي)، حيث تدرك مديرات ومربيات رياض الأطفال اللواتي يحملن مؤهلاً علمياً (توجيهي) أن هناك معوقات لتطبيق جودة البيئة التربوية في رياض الأطفال أكثر من اللواتي يحملن مؤهل علمي دبلوم أو بكالوريوس فأعلى؛ ويعتقد الباحث أن المربيات ممن يحملن مؤهل توجيهي أكثر إستقراراً ورضا وقناعة بالعمل قي مرحلة رياض الأطفال من اللواتي يحملن مؤهل علمي دبلوم أو بكالوريوس فأعلى وذلك لقلة

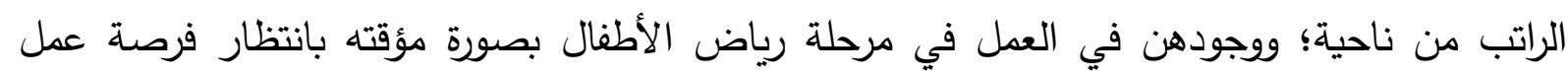
أخرى تتاسب مع راتبهن ومؤهلاتهن العلمية من ناحية أخرى. وتتفق هذه النتيجة مع نتائج دراسة كل من: (صاصيلا، 2010؛ أبو دقة وآخرون، 2007؛ احمد، 2013)، فقد بينت النتائج بالنسبة لكفاءة المربيات أن جميعهن لديهن شهادة الثانوية العامة وثلث أفراد العينة لديهن مؤهل جامعي إلى جانب تدني راتب المربيات وقلة خبرتهن في مجال الطفولة المبكرة. ولإيجاد الفروق الإحصائية لمعوقات تطبيق جودة البيئة التربوية في رياض الأطفال تبعاً لمتغير سنوات الخدمة، استخدم الباحث اختبار (ت) (T-test) لمجموعتين مستقلتين لدلالة الفروق على الدرجة الكلية للأداة. كما يوضحه الجدول (7).

جدول (7)

المتوسطات الحسابية للارجة الكلية للمجالين والدارجة الكلية تبعاً لمتغير سنوات الخدمة

\begin{tabular}{|c|c|c|c|}
\hline 11 سنة فأكثر & بين 6-10 سنوات & أقل من 6 سنوات & المجالات \\
\hline 0.27 & 0.21 & 0.33 & المعوقات المادية \\
\hline 0.27 & 0.33 & 0.21 & المعوقات الفنية \\
\hline 0.26 & 0.27 & 0.24 & الدرجة الكلية \\
\hline
\end{tabular}

ولاستخراج دلالة الفروق للارجة الكلية للمجالين والدرجة الكلية للأداة تبعاً لمتغير سنوات الخدمة عند العينة، تم استخدام تحليل التباين الأحادي (ANOVA) والجدول(8) يبين ذلك. 
جدول (8) (ل)

نتائج تحليل التباين الأحادي (ANOVA) للمجالين واللارجة الكلية تبعاً لمتغير سنوات الخدمة

\begin{tabular}{|c|c|c|c|c|c|c|}
\hline مستوى الدلالة & ف & متوسط المربعات & درجات & المربعات & مصدر التباين & المجالات \\
\hline \multirow{3}{*}{0.04} & \multirow{3}{*}{3.28} & 0.10 & 2 & 0.20 & بين المجموعات & \multirow[t]{3}{*}{ المعوقات المادية } \\
\hline & & \multirow[t]{2}{*}{0.03} & 171 & 3.90 & داخل المجموعات & \\
\hline & & & 173 & 4.09 & المجموع & \\
\hline \multirow{3}{*}{0.07} & \multirow{3}{*}{2.66} & 0.12 & 2 & 0.23 & بين المجموعات & \multirow[t]{3}{*}{ المعوقات الفنية } \\
\hline & & \multirow[t]{2}{*}{0.04} & 171 & 5.63 & داخل المجموعات & \\
\hline & & & 173 & 5.86 & المجموع & \\
\hline \multirow{3}{*}{0.90} & \multirow{3}{*}{0.11} & 0.00 & 2 & 0.00 & بين المجموعات & \multirow[t]{3}{*}{ جميع الفقرات } \\
\hline & & \multirow[t]{2}{*}{0.02} & 171 & 2.67 & داخل المجموعات & \\
\hline & & & 173 & 2.68 & المجموع & \\
\hline
\end{tabular}

* دال إحصائياً عند مستوى ( 2 (0.05).

يتضح من الجدول (8) السابق عدم وجود فروق ذات دلالة إحصائية لمعوقات تطبيق جودة البيئة التربوية في رياض الأطفال من وجهة نظر مديرات ومربيات رياض الأطفال في فلسطين حسب مجال (المعوقات الفنية) والدرجة الكلية للأداة تعزى لمتغير سنوات الخدمة. وهذا يؤكد تقارب توجهات مديرات ومربيات رياض الأطفال في فلسطين على جميع فقرات مجال الدراسة (المعوقات الفنية). كما يتبين وجود فروق ذات دلالة إحصائية لمعوقات تطبيق جودة البيئة التربوية في رياض الأطفال من وجهة نظر مديرات ومربيات رياض الأطفال في فلسطين حسب مجال المعوقات المادية وذلك لصالح من لديهم خدمة تقل عن (6) سنوات. ويعود ذلك الى حداثة سنوات الخدمة للمديرات والمربيات العاملات في رياض الأطفال، وتثير هذه النتيجة إلى ارتباط الوعي نحو تطبيق جودة البيئة التربوية في رياض الأطفال بالمديرات والمربيات الأقل خدمة؛ وربما سبب ذلك حداثة التخرج من الدراسة وزيادة الحماس للعمل في مرحلة رياض الأطفال مقارنة باللواتي لديهن خدمة أطول، والأقدم في التخرج. ولإيجاد الفروق الإحصائية لمعوقات تطبيق جودة البيئة التربوية في رياض الأطفال تبعاً لمتغير الحالة الاجتماعية، استخدم الباحث اختبار (ت) (T-test) لمجموعتين مستقلتين لدلالة الفروق على الدرجة الكلية للأداة. كما يوضحه الجدول (8). 
جلول (8)

المتوسطات الحسابية للارجة الكلية للمجالين والدرجة الكلية تبعاً لمتغير الحالة الاجتماعية

\begin{tabular}{|c|c|c|c|c|}
\hline أرملة & مطلقة & متزوجة & عزباء & المجالات \\
\hline 0.25 & 0.22 & 0.19 & 0.25 & المعوقات المادية \\
\hline 0.25 & 0.27 & 0.30 & 0.25 & المعوقات الفنية \\
\hline 0.10 & 0.24 & 0.38 & 0.10 & الدرجة الكلية \\
\hline
\end{tabular}

ولاستخراج دلالة الفروق للدرجة الكلية للمجالين والدرجة الكلية للأداة تبعاً لمتغير الحالة الاجتماعية عند العينة، تم استخدام تحليل التباين الأحادي (ANOVA). والجدول (9) يبين ذلك. جدول (9)

نتائج تحليل التباين الأحادي (ANOVA) للمجالين والدارجة الكلية تبعاً لمتغير الحالة الاجتماعية

\begin{tabular}{|c|c|c|c|c|c|c|}
\hline مستوى & ف & متوسط المربعات & درجات & المربعات & مصدر التباين & المجالات \\
\hline \multirow{3}{*}{0.33} & \multirow{3}{*}{1.15} & 0.04 & 3 & 0.11 & بين المجموعات & \multirow[t]{3}{*}{ لمعوقات المادية } \\
\hline & & \multirow[t]{2}{*}{0.03} & 170 & 3.99 & داخل المجموعات & \\
\hline & & & 173 & 4.09 & المجموع & \\
\hline \multirow{3}{*}{0.07} & \multirow{3}{*}{2.42} & 0.10 & 3 & 0.31 & بين المجموعات & \multirow[t]{3}{*}{ المعوقات الفنية } \\
\hline & & \multirow[t]{2}{*}{0.04} & 170 & 5.54 & داخل المجموعات & \\
\hline & & & 173 & 5.86 & المجموع & \\
\hline \multirow{3}{*}{0.36} & \multirow{3}{*}{1.08} & 0.02 & 3 & 0.07 & بين المجموعات & \multirow[t]{3}{*}{ جميع الفقرات } \\
\hline & & \multirow[t]{2}{*}{0.02} & 170 & 2.61 & داخل المجموعات & \\
\hline & & & 173 & 2.68 & الدجموع & \\
\hline
\end{tabular}

يتضح من الجدول (9) السابق عدم وجود فروق ذات دلالة إحصائية لمعوقات تطبيق جودة البيئة التربوية في رياض الأطفال من وجهة نظر مديرات ومربيات رياض الأطفال في فلسطين حسب مجالي (المعوقات المادية، المعوقات الفنية) والدرجة الكلية للأداة تعزى لمتغير الحالة الاجتماعية. وهذا يؤكد تقارب توجهات مديرات ومربيات رياض الأطفال في فلسطين على فقرات مجالي الدراسة وجميع فقرات الأداة.

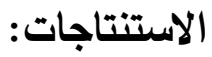

يتضح من الدراسة الحالية الاستتاجات الآتية:

1. قلة المعايير الجيدة في معظم رياض الأطفال في فلسطين والتي تتعلق بمواصفات البيئة التربوية المناسبة وخاصة فيما يتعلق بمواصفات البناء للروضة، إذ تبين عدم تناسب المرافق والتجهيزات مع ذوي الحاجات الخاصة، وعدم تناسب الحمامات مع عدد الأطفال، وعدم توافر ساحات وملاعب. 
2. قلة المعايير الجيدة في معظم رياض الأطفال في فلسطين والتي تتعلق بمواصفات البيئة التربوية المناسبة وخاصة فيما يتعلق بمواصفات تجهيزات الروضة، إذ بينت النتائج أن المواد التربوية من وسائل تعليمية وألعاب تعليمية وأجهزة الحاسوب غير متوفرة بشكل كافٍ في رياض الأطفال. ويمكن أن تعزى أسباب هذا القصور إلى أسباب متعددة أهمها: 1. قلة الموارد المادية للروضة.

2. ضعف وقلة مؤهلات مديرات ومربيات الرياض للعمل قي رياض الأطفال. 3. تجاوز الأنظمة والتشريعات في كثير من القضايا والمسائل المتعلقة بالرياض خاصة فيما يتعلق بشروط البناء والتجهيزات اللازمة والعاملين في الرياض. التوصيات والمقترحات:

يقدم الباحث التوصيات والمقترحات الآتية والتي قد تسهم في تجويد البيئة التربوية: 1. توفير الدعم والإمكانيات المالية لمؤسسات رياض الأطفال وذلك من خلال: أ. دعم الدولة من خلال تخصيص بند في ميزانية التعليم لدعم هذه المرحلة أسوة ببقية الدول في العالم خاصة المتقدمة منها. ب. توعية الأهالي والمجتمع المحلي ورجال الأعمال والمؤسسات الأهلية بأهمية التبرع ودعم رياض الأطفال.

ج. إقامة الحفلات والمهرجانات الخيرية وتخصيص ريعها لصالح هذا القطاع. د. إعفاء رياض الأطفال من الضرائب المفروضة عليهم من دوائر الضريبة في فلسطين أسوة ببقية دول

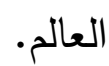
هـ تقديم التسهيلات اللازمة بالإعفاء الضرببي عن الوسائل التعليمية وتجهيزات الروضة وألعاب الأطفال

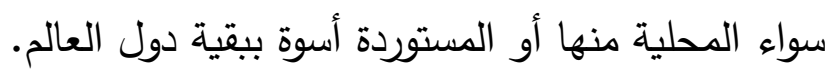
و. تقديم التسهيلات اللازمة للمختصين وأصحاب المؤهلات العلمية في مجال رياض الأطفال بالحصول على قروض ودعم لإنشاء وتجهيز مباني رياض الأطفال تضمن جودة البيئة التعليمية.

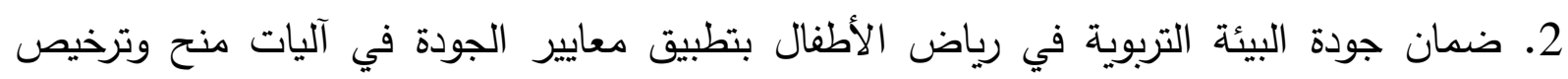
الروضة على مبنى وتجهيزات الروضة والعاملين فيها. 3. رفع رواتب العاملات في رياض الأطفال بضمان تطبيق الحد الأدنى للأجور على الأقل. 4. تأسيس كليات تهتم بتأهيل خريجات مؤهلات للعمل في رياض الأطفال أسوة ببقية دول العالم. 
أولاً: المراجع العربية:

1. أبو دقة، سناء وآخرون، دراسة تقويمية لجودة التعليم في رياض الأطفال بقطاع غزة. غزة، مجلة الجامعة الاسلامية، الدراسات الإنسانية، م15، ع(2)، (2007).

2. أحمد، ابراهيم أحمد، تطبيق الجودة والاعتماد في المدارس، دار الفكر العربي، القاهرة، (2007). 3. احمد، آيات فاروق حسين، معوقات تطبيق معايير الجودة والاعتماد في مرحلة رياض الأطفال "دراسة ميدانية". رسالة ماجستير غير منشورة، كلية التربية، جامعة أسيوط، مصر ، (2013).

4. بهادر، سعدية، برامج تربية أطفال ما قبل المدرسة بين النظرية والتطبيق. الخدمات للطباعة، القاهرة، (2004).

5. بهادر ، سعدية محمد علي، برامج تربية أطفال ما قبل المدرسة، دار المسيرة، عمان، (2003). 6. خلف، أمل، مدخل إلى رياض الأطفال، عالم الكتب، القاهرة، (2005). 7. راشد، أمال غالب وآخرون، إمكانية تطبيق ثقافة الجودة الثاملة في المؤسسات التعليمية. الدجلة

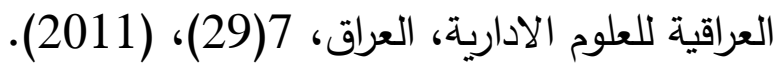
8. الزبون، إسلام، معايير الجودة لرياض الأطفال، (2017). https://mawdoo3.com/\%D9\%85\%D8\%B9\%D8\%A7\%D9\%8A\%D9\%8A\%D8\%B 1_\%D8\%A7\%D9\%84\%D8\%AC\%D9\%88\%D8\%AF\%D8\%A9_\%D9\%84\%D8\%B 1\%D9\%8A\%D8\%A7\%D8\%B6_\%D8\%A7\%D9\%84\%D8\%A3\%D8\%B7\%D9\%81 \%D8\%A7\%D9\%84

9. الزواوي، خالد محمد، الجودة الثاملة في التعليم. مجموعة النيل العربية، القاهرة، (2003). 10. السرور، ناديا، التعليم ما قبل المدرسي في المملكة الأردنية الهاثمية، دراسة ميدانية. الجامعة الأردنية، مجلة دراسات سلسلة العلوم الإنسانية والاجتماعية، عمان، م(26)، ع (2)، (1999). 11. سعفان، أماني إبراهيم، معايير الجودة الثاملة في رياض الأطفال (الواقع والمأمول). رسالة ماجستير غير منشورة، جامعة الاسكندرية، كلية رياض الأطفال، مصر ، (2008). 12. السنيدي، عمر بن عبدالعزيز بن عمر، معوقات تطبيق معايير إدارة الجودة الثاملة في الإدارة

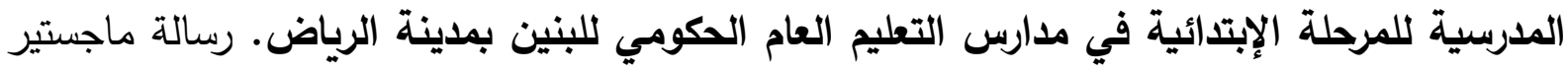

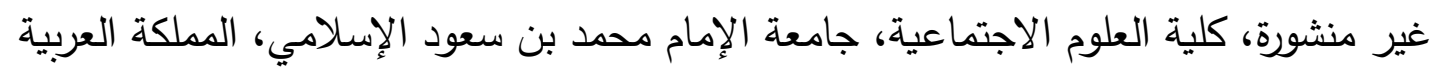
السعودية، (2012). 
13. صاصيلا، رانية، تصور مقترح لضمان جودة البيئة التربوية في رياض الأطفال في الجمهورية العببة السورية. مجلة جامعة دمشق، جامعة دمثق، م(26)، ع(3)، (2010).

14. الثال، محمود مصطفى محمود وآخرون، متطلبات تهيئة مدارس التعليم الأساسي بمحافظة البحيرة لتطبيق الاعتماد وضمان الجودة-دراسة ميدانية. مجلة كلية التربية، جامعة الزقازيق، ع(64)،

15. الثتيحي، إيناس سعيد عبدالحميد، أبعاد ثقافة الجودة برياض الأطفال من منظور المعلمات بمحافظة المنوفية. مجلة الطفولة العربية، مصر ، ع(65)، (2015). 16. شريف، السيد عبدالقادر، ثقافة الجودة في إدارة رياض الأطفال وتطبيقاتها. دار الجوهرة، القاهرة،

17. طلبة، جابر محمود، البحث التزبوي في مجال تربية الطفل. مكتبة الإيمان، دصر ، (2004). 18. علي أحدد، نافز أيوب، تقييم برامج ومناهج اطفال ذوي الاحتياجات الخاصة وفق معايير الجودة.

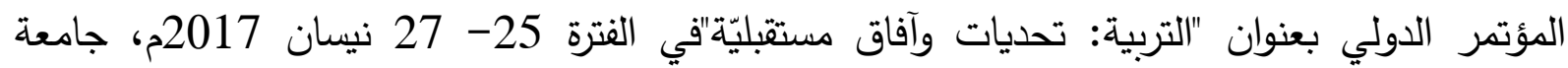
اليرموك- كلية التربية، إربد، الأردن، (2017). 19. عبدالحميد، أماني إبراهيم، معايير الجودة الثاملة في مؤسسات رياض الأطفال الواقع والمأمول. رسالة ماجستير غير منشورة، جامعة الاسكندرية، جمهورية مصر العربية، (2008).

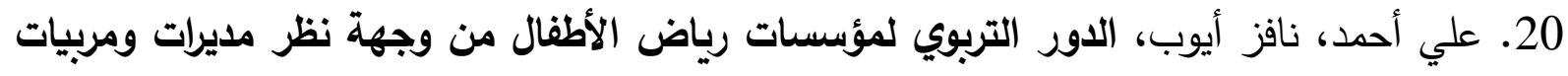

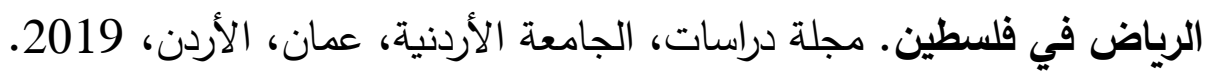

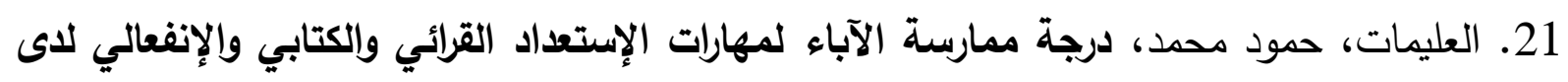
أطفال ما قبل المدرسة. المنارة، م(16)، ع(1)، الأردن، جامعة آل البيت، (2013).

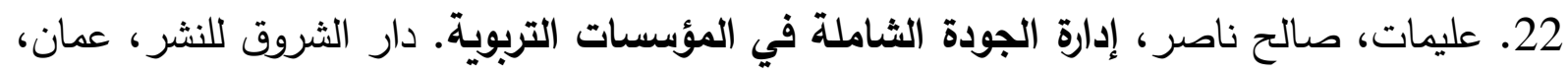
.(2004) 23. قطامي، نايفة، تقويم نمو الطفل. دار المسيرة، عمان، (2008). 24. فايد، عبد الستار محروس عبد الستار، تصور مقترح للتظب على معوقات تطبيق إدارة الجودة الثاملة في مؤسسات رياض الأطفال بجمهورية مصر العببية. رسالة ماجستير غير منشورة، كلية التربية، جامعة الفيوم، الفيوم، مصر ، (2013). 
25. لبابنه، أحمد حسن، درجة تحقيق مؤسسات رياض الأطفال للتربية المتكاملة لأطفال ما قبل المدرسة. جامعة البلقاء التطبيقية، كلية اربد الجامعية، الأردن، (2010). 26. مسعود، أمل سيد، رياض الأطفال في مصر بين الواقع والمأمول. مجلة مستقبل التربية العربية، ק)

27. سليمان، ميسون أحمد مصطفى، فاعلية برنامج يستند إلى الإرشاد باللعب في خفض النشاط

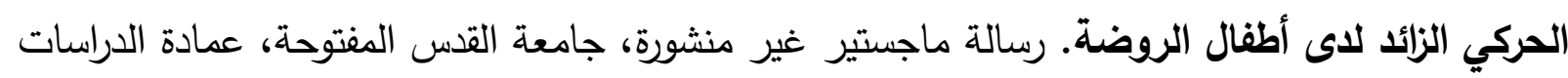
العليا والبحث العلمي، رام الله، فلسطين، (2018).

28. النقيب، إيمان، مباني وتجهيزات رياض الاطفال بمحافظة الاسكندرية دراسة تقويمية. مجلة كلية التربية، ع(70) ج(2)، جامعة الزقازيق، الزقازيق، (2011).

29. وزارة التربية والتعليم العالي، قانون التعليم رقم (1) لسنة 2013م. رام الله، فلسطين، (2013). 30. اليونسكو (المنظمة العربية للتربية والثقافة والعلوم)، مباني رياض الأطفال وتجهيزاتها في الوطن العبي. تونس، (1991).

31. اليونيسف، المبادرة الأردنية لتنمية الطفولة المبكرة، جعل الأردن جديرا بالأطفال. مكتب اليونيسف الإقليمي للشرق الأوسط وشمال افريقيا، سلسلة التعلم(2)، عمان، الأردن، (2009).

ثانياً: المراجع الاجنبية:

\section{References}

1. Forment, E. Developing on Internal Quality Culture in European Universities. Report on the quality culture project round 11. European University Association, (2004).

2. Hespe, D. Standards for preschool education. (2014).

www.state.nj.us/education/ece/guide/standards.pdf.

3. Hirsh, $E$. The basic principles of high quality practice in kindergartens are by teachers. (2014). www.doe.mass.edu/kindergarten/HQ-

Kindergarten.docx.

available at: http://my.execpc.com/-jwoods/6values.htm.

4. Lowenthal, B. Teaching Social Skills to Preschoolers. Child and Education, spring, (1996). 
5. Ontario Ministry of Education. Evaluation of the role of kindergartens in the achievement of students in the first and twelfth grades .Ontario Ministry of Education, Ontario, (2016).

https://www.ncbi.nlm.nih.gov/pmc/articles/PMC2757260/.

6. Owens, K.B. Child \& Adolescent development. An integrated approach. Australia: Wadsworth, Thomson learning, (2002).

7. Salrana, R.G. The girls Education Initiative in Egypt. Amman, (2008).

8. Tungkunanan, P., Leekitchwatana, P., Pimsarn, N. \& Chumnum, S. Strategic Plan for Developing Quality Culture at eastern School of the Office of Vocation Education Commission. Thailand. ABAC Journal. 128(2), P52-63, (2008).

9. Wolff, K. Introduction to the Forum in Jensen. Embedding Quality Culture in Higher Education: A Selection of Papers from the $1^{\text {st }}$ European Forum for Quality Assurance. Belgium: European University Association, (2006).

10. Woods, J. The Six Values of a Quality culture. CWL Publishing Enterprises, (2010). available at: http://my.execpc.com/-jwoods/6values.htm. 